\title{
Explosive Nucleosynthesis of Weak r-Process Elements in Extremely Metal-Poor Core-Collapse Supernovae
}

\author{
Natsuko Izutani ${ }^{1}$, Hideyuki Umeda ${ }^{1}$ and Nozomu Tominaga ${ }^{2}$ \\ ${ }^{1}$ Department of Astronomy, School of Science, University of Tokyo, Hongo, Tokyo 113-0033, Japan \\ izutani@astron.s.u-tokyo.ac.jp; umeda@astron.s.u-tokyo.ac.jp \\ ${ }^{2}$ National Astronomical Observatory, 2-21-1 Osawa, Mitaka, Tokyo 181-8588, Japan \\ nozomu.tominaga@nao.ac.jp \\ Accepted to ApJ: October 29, 2008
}

\begin{abstract}
There have been attempts to fit the abundance patterns of extremely metal-poor stars with supernova nucleosynthesis models for the lighter elements than Zn. On the other hand, observations have revealed that the presence of EMP stars with peculiarly high ratio of "weak r-process elements" Sr, Y and Zr. Although several possible processes were suggested for the origin of these elements, the complete solution for reproducing those ratios is not found yet. In order to reproduce the abundance patterns of such stars, we investigate a model with neutron rich matter ejection from the inner region of the conventional mass-cut. We find that explosive nucleosynthesis in a high energy supernova (or "hypernova") can reproduce the high abundances of Sr, $\mathrm{Y}$ and $\mathrm{Zr}$ but that the enhancements of Sr, $\mathrm{Y}$ and $\mathrm{Zr}$ are not achieved by nucleosynthesis in a normal supernova. Our results imply that, if these elements are ejected from a normal supernova, nucleosynthesis in higher entropy flow than that of the supernova shock is required.
\end{abstract}

Subject headings: supernovae: general — nuclear reactions, nucleosynthesis, abundances

\section{INTRODUCTION}

The abundance patterns of extremely metalpoor (EMP) stars are useful in studying nucleosynthesis in massive supernovae (SNe). Population (Pop) III stars are usually considered to be massive stars. Some of them might become black holes without supernova explosions, but some should have exploded as supernovae to initiate the first metal enrichment in the early universe. The stars born from the gas enriched by the Pop III SNe are Pop II stars with low metallicity. Lowmass Pop II stars have long lifetimes and might be observed as extremely metal poor (EMP) stars with $[\mathrm{Fe} / \mathrm{H}] \lesssim-3$. (Here, $[\mathrm{A} / \mathrm{B}]=\log _{10}\left(N_{\mathrm{A}} / N_{\mathrm{B}}\right)$ - $\log _{10}\left(N_{\mathrm{A}} / N_{\mathrm{B}}\right)_{\odot}$, where the subscript " $\odot$ " refers the solar value and $N_{\mathrm{A}}$ and $N_{\mathrm{B}}$ are the abundances of elements $\mathrm{A}$ and $\mathrm{B}$, respectively.) Therefore, a EMP star may reflect the nucleosynthetic result of a Pop III SN and constrain properties of the

\section{Pop III SN.}

There have been attempts to actually fit the abundance patterns of EMP stars with the supernova nucleosynthesis models. For example, using the mixing-fallback model proposed by Umeda \& Nomoto (2002) (hereafter UN02) and Umeda \& Nomoto (2003) (hereafter UN03) mimicking aspherical explosion effects (e.g., Tominaga 2009), they showed that the abundance patterns of the elements from $\mathrm{C}$ to $\mathrm{Zn}$ of carbon-normal EMP stars and carbon-rich EMP stars can be successfully reproduced by energetic core-collapse SN ("hypernova", hereafter $\mathrm{HN}$ ), models and faint SN models, respectively (UN02; UN05; Tominaga et al. 2007), while those of very metal poor (VMP) stars $(-3 \lesssim[\mathrm{Fe} / \mathrm{H}] \lesssim-2)$ can be reproduced by normal core-collapse SN models or the IMF-integration of hypernova and normal core-collapse SN models (Tominaga et al. 2007). It is important to note that the observed EMP stars are so far all 
explained by the pollutions by core-collapse $\mathrm{SNe}$ with initial stellar masses $11 M_{\odot} \lesssim M \lesssim 130 M_{\odot}$ and no evidence of pair instability $\mathrm{SN} \mathrm{1}^{1}$ with initial stellar masses $140 M_{\odot} \lesssim M \lesssim 300 M_{\odot}(\mathrm{UN} 02$, see also Chieffi \& Limongi 2002; UN03; Umeda \& Nomoto 2005, hereafter UN05; Heger \& Woosley 2002, 2008).

These previous SN models do not eject elements heavier than $\mathrm{Zn}$ in a sizeable amount, and this is consistent with the abundance of some EMP stars. However, there are also EMP stars showing enhancements of neutron-capture elements. Some of them show abundance patterns almost identical to the solar system r-process pattern for $\mathrm{Sr}$ and heavier elements (e.g., Sneden et al. 2000; Hill et al. 2002). One example of such a star is CS22892-052 and called as a main "r-process star" (Sneden et al. 2003). The process producing heavy neutron capture elements $(\sim \mathrm{Ba}-\mathrm{U})$ is referred to as "main" r-process (e.g., Truran et al. 2002; Wanajo \& Ishimaru 2006). On the other hand, there are other EMP stars that require another neutron-capture process referred sometimes as "LEPP" (lighter element primary process) or "weak r-process" (Travaglio et al. 2004; Wanajo \& Ishimaru 2006). Travaglio et al. (2004) reported EMP stars with abundances of Sr, Y, and $\mathrm{Zr}$ which cannot be explained by the s-process or main r-process. In the weak r-process stars, the elements with intermediate mass $(37 \leq \mathrm{Z} \leq 47$, i.e., from $\mathrm{Rb}$ to $\mathrm{Ag}$ ) elements show moderate enhancements with respect to heavy ones $(\mathrm{Z} \geq 56$, i.e., heavier than $\mathrm{Ba})$. More recently Francois et al. (2007) showed several other examples of the weak r-process stars. There are evidences of the existence of weak r-process but its origin is unknown.

Several possible mechanisms to produce the weak r-process elements are proposed. Wanajo et al. (2001) presented calculations of r-process nucleosynthesis in neutrino-driven winds from a proto-neutron stars. They showed that the abundance pattern of weak r-process is reproduced when the main r-process nucleosynthesis is failed. The nucleosynthesis in neutrino-driven winds was also studied in Hoffman et al. (1996) by taking the electron fraction $Y_{\mathrm{e}}$ of the wind matter as a free parameter. They showed that weak r-process ele-

\footnotetext{
${ }^{1}$ Pair instability SNe explode by the explosive oxygen burning, before the onset of Fe core-collapse.
}

ments may be synthesized for low $Y_{\mathrm{e}}(<0.47)$. Although the production of weak r-process elements in neutrino-driven winds was suggested, it is difficult to give a detailed yield because the physical conditions and ejected mass depend on unknown supernova explosion mechanisms.

Explosive nucleosynthesis in low $Y_{\mathrm{e}}$ matter was also studied in the context of multi-dimensional explosion models (Janka et al. 2003; Pruet et al. 2003). They showed that small amounts of low $Y_{\mathrm{e}}$ $(\lesssim 0.46)$ matter as well as high $Y_{\mathrm{e}}(\lesssim 0.56)$ matter are ejected from a hot bubble just outside a protoneutron star. The high $Y_{\mathrm{e}}(\lesssim 0.56)$ matter is suggested to be ejected even in the one-dimensional cases (e.g., Frölich et al. 2006). On the other hand, the ejection of low $Y_{\mathrm{e}}$ matter is driven by the convection in the hot bubble, and thus essentially the multi-dimensional phenomenon. Janka et al. (2003) suggested that the low $Y_{\mathrm{e}}$ matter contains the weak r-process elements ( $\mathrm{Sr}, \mathrm{Y}$ and $\mathrm{Zr}$ ) to explain the Galactic abundances, but a detailed nucleosynthesis calculation did not confirm the production of these elements (Pruet et al. 2005).

In this paper, we investigate the physical conditions to produce sufficient amounts of the weak r-process elements ( $\mathrm{Sr}, \mathrm{Y}$ and $\mathrm{Zr}$ ) and discuss whether core-collapse $\mathrm{SNe}$ with a slight modification can be compatible with the observed abundances of the weak r-process elements in the EMP stars. In order to do this, we assume that small amount of low $Y_{\mathrm{e}}$ matter is ejected by the multidimensional effects, which may be driven by the convection in a hot bubble (Janka et al. 2003) or jets in a jet-like explosion (e.g., Maeda \& Nomoto 2003) or a collapsar model (e.g., Pruet et al. 2003, 2004; Popham, Woosley \& Fryer 1999). The entropy of the low $Y_{\mathrm{e}}$ matter flow may depend on the ejection mechanism. We assume that the matter flow has the same entropy as the supernova shock wave. Jet-like explosion or collapsar models may describe HNe. However, they contain many unknown parameters, and the innermost $Y_{\mathrm{e}}$ of the ejecta depends on those parameters. On the other hand, the simulations of Janka et al. (2003) contain less input parameters, so the obtained $Y_{\mathrm{e}}$ profile is more reliable, though their simulations are about normal SNe. We are interested in the EMP stars, and their progenitor may be more massive and explode energetically, i.e., may become HNe. Therefore, we vary $Y_{\mathrm{e}}$ beyond the range given by 
the simulation in Janka et al. (2003). Although we have multi-dimensional effects in mind, we only perform one-dimensional calculations in this paper, because it is often useful to make a large parametric search to disclose the essence of physics.

In $\S 2$, we show observational trends of [ $\mathrm{Sr}, \mathrm{Y}, \mathrm{Zr} / \mathrm{Fe}]$. In $\S 3$, we describe our progenitor and explosion models. In $\S 4$, we present weak r-process nucleosynthesis and specify conditions mention our assumption applying to our models in order to reproduce reproducing the observational $[\mathrm{Sr}, \mathrm{Y}, \mathrm{Zr} / \mathrm{Fe}]$. We also compare our yields with 4 EMP stars which have peculiarly high $[\mathrm{Sr}, \mathrm{Y}, \mathrm{Zr} / \mathrm{Fe}]$. In $\S 5$, summaries and discussions are given.

\section{OBSERVATIONAL DATA}

Since we are interested in the weak r-process elements in the EMP stars, we select stars with $[\mathrm{Fe} / \mathrm{H}] \lesssim-2.8$ from Cayrel et al. (2004) and use their data from carbon to zinc. Observations of [Sr, Y,Zr/Fe] are taken from Honda et al. (2006) for HD122563 and Francois et al. (2007) for the other stars.

Taking the previous works on the weak rprocess into consideration, we use two abundance ratios as a diagnostic to distinguish "main rprocess stars" and "weak r-process stars". They are relative numbers of $\mathrm{Sr}$ and $\mathrm{Ba}, \mathrm{Sr} / \mathrm{Ba}$, and $\mathrm{Y}$ and $\mathrm{Eu}, \mathrm{Y} / \mathrm{Eu}$. We use $\log \left(N / N_{\mathrm{H}}\right)_{\odot}$ from Anders \& Grevesse (1989). A main r-process star CS22892-052 has $[\mathrm{Sr} / \mathrm{Ba}]=-0.57$ and $[\mathrm{Y} / \mathrm{Eu}]$ $=-1.16$. Therefore, if a EMP star has $[\mathrm{Sr} / \mathrm{Ba}]$ $>-0.57$ and $[\mathrm{Y} / \mathrm{Eu}]>-1.16$, we consider the star as a weak r-process star, otherwise as a main r-process star (see also Aoki et al. 2005). Figure 1 shows $[\mathrm{Sr} / \mathrm{Fe}],[\mathrm{Y} / \mathrm{Fe}]$, and $[\mathrm{Zr} / \mathrm{Fe}]$ vs. $[\mathrm{Fe} / \mathrm{H}]$ of the weak r-process stars. Among 21 selected stars, 20 stars are with $-1 \lesssim[\mathrm{Sr}, \mathrm{Y}, \mathrm{Zr} / \mathrm{Fe}] \lesssim 1$.

\section{METHOD \& MODEL}

The calculation method and other assumptions are the same as described in Umeda et al. 2000 (hereafter UNN00), UN02, UN05 and Tominaga et al. 2007, except for the size of the nuclear reaction networks. In this paper, we adopt the Pop III progenitors as in UN05 and apply the model with $M$ $=13 M_{\odot}$ and $E_{51}=1.5$ (hereafter model-1301), the one with $M=25 M_{\odot}$ and $E_{51}=1$ (hereafter model-2501), and the one with $M=25 M_{\odot}$ and
$E_{51}=20$ (hereafter model-2520). Model-1301 and model-2501 are normal SN models, and model2520 is a HN model. Detailed nucleosynthesis is calculated as a postprocessing after the hydrodynamical calculation with a simple $\alpha$-network. The isotopes included in the post process calculations are 809 species up to ${ }^{121} \mathrm{Pd}$ (see Table 1 ). We note that a neutrino process during explosive burning (Yoshida et al. 2008; Woosley \& Weaver 1995) is not taken into account. The abundance distributions after the SN explosion for model-1301, model-2501 and model-2520 are shown in Figure 2 . We obtain the final yields by setting the inner boundary of the ejected matter, a mass-cut $\left(M_{\text {cut }}\right)$ as we describe in the next section.

\subsection{MASS-CUT}

In this section we summarize the abundance pattern of SN ejecta when a "conventional" masscut is adopted. The "conventional" means that the mass-cut is chosen to eject a reasonable amount of ${ }^{56} \mathrm{Ni}$. Although previously the mass-cut is often chosen to eject $0.07 M_{\odot}$ of ${ }^{56} \mathrm{Ni}$ reproducing the brightness of normal SNe as SN1987A (e.g., Nomoto et al. $2003 \mathrm{~b}$ ), we set $M_{\text {cut }}=1.59 M_{\odot}$ for model-1301, $1.76 M_{\odot}$ for model-2501 and 2.31 $M_{\odot}$ for model-2520 to yield $[\mathrm{Si} / \mathrm{Fe}] \simeq\left[\mathrm{Si} /{ }^{56} \mathrm{Ni}\right]$ $\sim 0.4$. As a result, $13 M_{\odot}$ model eject a similar amount of ${ }^{56} \mathrm{Ni}$ to $\mathrm{SN} 1987 \mathrm{~A}\left(\sim 0.07 M_{\odot}\right)$, but $25 M_{\odot}$ models eject large amounts of ${ }^{56} \mathrm{Ni}(\sim 0.5$ $\left.M_{\odot}\right) \sqrt{2}$. In Figure 3, the abundance patterns from $\mathrm{Si}$ to $\mathrm{Ru}$ are compared with those of EMP stars. This figure shows that the adopted $M_{\text {cut }}$ s yield a rather good agreement between the predicted and the observed abundance ratios for most of the elements above Si. On the contrary, $[\mathrm{Sr}, \mathrm{Y}, \mathrm{Zr} / \mathrm{Fe}]$ in the models are much lower than those observed in the "weak r-process stars".

\section{WEAK r-PROCESS NUCLEOSYN- THESIS}

As mentioned in $\S 3$, the models with the "conventional" mass-cut do not reproduce $-1 \lesssim$ $[\mathrm{Sr}, \mathrm{Y}, \mathrm{Zr} / \mathrm{Fe}] \sim 1$. In this section, we study the conditions to produce weak r-process elements. We take into account of the uncertainty of $Y_{\mathrm{e}}$ and

\footnotetext{
${ }^{2}$ In the models assuming the mixing-fallback effects, the actual amount of the ejected ${ }^{56} \mathrm{Ni}$ mass is smaller than this value. See e.g., Table 3 and section 4.4 below.
} 
assume some ejection of matter from regions below $M_{\text {cut }}$.

\section{1. $Y_{\mathrm{e}}$ Uncertainty and Mass Ejection from the Region below $M_{\text {cut }}$}

Recent theoretical multi-D hydrodynamical simulations of core collapse supernova have shown that the presupernova value of $Y_{\mathrm{e}}$ can be modified during the explosion, even significantly, in the innermost zones of the exploding envelope. In Figure 4 we schematically depict the value of $Y_{\mathrm{e}}$ before and after the explosion. The presupernova value shown is for the model when the central density is $\sim 10^{10} \mathrm{~g} \mathrm{~cm}^{-3}$. After that time, the electron capture significantly reduces $Y_{\mathrm{e}}(\lesssim 0.4)$ in the inner part, but the very neutron-rich matter is rarely ejected.

Recent simulations have shown that not only neutron-rich $\left(Y_{\mathrm{e}}<0.5\right)$ but also proton-rich $\left(Y_{\mathrm{e}}>\right.$ 0.5) regions appear after explosion(e.g., Frölich et al. 2006). The $Y_{\mathrm{e}}$ distributions based on an actual 2D-simulations is, for example, given in Figure 4 of Pruet et al. (2006). Figure 4 shows the assumed $Y_{\mathrm{e}}$ profile mimicking the results of such simulations. Those simulations have shown that a density just above a proto-neutron star surface rapidly decreases after the supernova shockwave passes through a Fe-core. This region is often called a hot bubble, in which $Y_{\mathrm{e}}$ is set by a competition between different lepton capture processes on free nucleons. At the beginning of the explosion, an excess of electron neutrinos over antineutrinos makes the matter tend to be proton-rich (Qian and Woosley 1996). Recent detailed one- and twodimensional simulations have shown that some of these proton-rich matter is actually ejected. In the later stages, the fluxes and spectral change of neutrinos make $Y_{\mathrm{e}}$ less than 0.5. 2D simulations by Janka et al. (2003) have shown that not only the proton-rich matter but also some neutron-rich matter $\left(Y_{\mathrm{e}} \gtrsim 0.46-0.47\right)$ is ejected. This is because the hot bubble is convective and some of the inner matter can be dragged outside.

Although these previous calculations are for less massive normal supernovae, the similar mechanism may work for more massive supernova. Even if the explosion mechanism is completely different, the inner matter may be carried outside along the jets in a jet-like explosions. Therefore, in the following we calculate nucleosynthesis in a deep re- gion of supernovae to estimate the total yield when the same amount of matter below the conventional mass cut, with $Y_{\mathrm{e}}$ arbitrarily changed with respect to the presupernova value, is ejected.

In order to perform nucleosynthesis calculations, we need histories of temperature and density for a given mass element. Strictly speaking, the histories depend on explosion models and how the matter is carried outside and cannot be represented by a one-dimensional model. To avoid complication, however, we carry out the same calculations with Section 3 but in the region below $M_{\text {cut }}$ and arbitrarily changing the $Y_{\mathrm{e}}$ in the progenitor model according to Figure 4. This approach helps simplifying the complicated problems and clarifying the essence of physics. With this assumption, the entropy of the low $Y_{\mathrm{e}}$ flow is $s / k_{\mathrm{b}} \sim 3$ for SNe and $\sim 15$ for HNe, which is similar value as the matter just above $M_{\text {cut }}$.

It has been long discussed that if a normal SN produces main r-process elements. This is because the $\mathrm{SN}$ has to eject quite high-entropy neutrino driven wind. As for the weak r-process, Wanajo et al. (2001), for example, showed that if the entropy of the neutrino driven wind is not high enough for the main r-process, a weak r-processlike pattern is obtained. However, whether a SN can eject such kind of mater is unpredictable because explosion simulations have not been succeeded. Therefore, we consider an extreme case that no neutrino-driven high-entropy matter but the supernova-shocked matter is ejected. The ejection of high entropy matter are discussed in the last part of Section 5 briefly and will be discussed in detail elsewhere.

\subsection{Parameter Dependences of "Com- plete Si-Burning"}

In this subsection, we show parameter dependences of the products of the complete-Si burning. The complete Si-burning takes place in the shocked matter attaining the maximum temperature of $\log _{10} T_{\max }>9.5$ and thus no unburned $\mathrm{Si}$ is left after the complete Si-burning. Since we are mainly interested in the ejection of low $Y_{\mathrm{e}}$ matter from the beneath of a conventional mass-cut, $M_{\text {cut }}$, we change $Y_{\mathrm{e}}$ in the region from 0.40 to 0.50 . Although Janka et al. (2003) showed the small amount of ejection of matter with $Y_{\mathrm{e}} \sim 0.56-0.46$ from the hot bubble region, we consider $Y_{\mathrm{e}}$ as low 
as 0.40 because the explosion mechanism is quite uncertain especially for hypernovae. In this paper we do not consider $Y_{\mathrm{e}}>0.5$ matter. Its effect is briefly discussed in Section 5 .

We use the temperature and density trajectories of the models 1301, 2501 and 2520 as $\S 3$. The difference from $\S 3$ is that we consider the deep region below $M_{\text {cut }}$. We denote the mass coordinate of the inner and outer boundaries of the region by $M_{1}$ and $M_{2}$, respectively, and take mass average in the region. $M_{2}$ is defined by the location where $X\left({ }^{28} \mathrm{Si}\right) \sim 10^{-3} . M_{1}$ is chosen at a point near Fe core surface. We note that the result is not sensitive to $M_{1}$ because density and temperature trajectories during nucleosynthesis is almost the same around $M_{1}$. The specific values taken are $\left(M_{1}, M_{2}\right)=\left(1.41 M_{\odot}, 1.64 M_{\odot}\right),\left(1.52 M_{\odot}, 1.92 M_{\odot}\right)$ and $\left(1.61 M_{\odot}, 2.69 M_{\odot}\right)$ for model-1301, model2501, and model-2520, respectively. Figure 5 illustrates the $Y_{\mathrm{e}}$ profile for the three models we have assumed.

Nucleosynthesis of this region basically proceeds as $\alpha$-rich freezeout. When the shock wave reaches the region, temperature rises rapidly and heavy elements are decomposed mainly into $\alpha$ particles. As the star expands and the temperature drops, $\alpha$-rich freezeout takes place with roughly constant $Y_{\mathrm{e}}$. The mass fraction of $\alpha$ at the maximum temperature and later stages depends on the entropy, i.e., temperature and density. More $\alpha$ is produced and heavier elements are synthesized for higher entropy explosions (e.g., UN02).

\subsection{1. $Y_{\mathrm{e}}$ Dependence}

In Figures 6-8, abundance ratios, [X/Fe], of the complete Si-burning products integrated over $M_{1}$ and $M_{2}$ are shown. The abundance ratios of heavy elements as a function of $Y_{\mathrm{e}}$ show non-monotonic behavior in Figure 6-8. This behavior depends not only on the abundance of $\mathrm{X}$, but also on that of Fe. For example, in Figure 6 and 7, Fe to heavy elements ratios, such as $\mathrm{Sr} / \mathrm{Fe}$, appear to be minimum for $Y_{\mathrm{e}} \sim 0.45$. This is because for $Y_{\mathrm{e}} \sim 0.45$ the most abundant isotope which becomes $\mathrm{Fe}$ is ${ }^{56} \mathrm{Fe}$ and not ${ }^{56} \mathrm{Ni}$. ${ }^{56} \mathrm{Fe}$ is produced relatively a lot for $Y_{\mathrm{e}} \sim 0.45$. Therefore, the reason for this non-monotonic behavior is not simple. These figures also show that for $Y_{\mathrm{e}} \gtrsim 0.49$, elements heavier than $\mathrm{Zn}$ are not efficiently produced compared to
Fe. We provide some explanations of the result paying attention to the abundance of $\mathrm{X}$ in the following paragraphs.

Absolute amounts of the synthesized weak rprocess elements are easily seen in Figure 9, which shows the mass fractions of $\mathrm{Sr}, \mathrm{Y}$ and $\mathrm{Zr}$ in the region. This figure shows that the abundances of these elements are relatively large for $Y_{\mathrm{e}} \lesssim 0.48$ and have a peak around $Y_{\mathrm{e}} \sim 0.43-0.46$. For $Y_{\mathrm{e}} \sim 0.42-$ 0.43 , most abundant isotopes that become Sr, Y and $\mathrm{Zr}$ are ${ }^{88} \mathrm{Kr}$, and ${ }^{89} \mathrm{Kr}$ and ${ }^{90} \mathrm{Kr}$, respectively. For $Y_{\mathrm{e}} \sim 0.45-0.46$, these are ${ }^{88} \mathrm{Sr},{ }^{89} \mathrm{Y}$ and ${ }^{90} \mathrm{Zr}$, respectively. Since these isotopes are all neutronrich having $Y_{\mathrm{e}} \equiv \mathrm{Z} / \mathrm{A} \sim 0.41-0.45$, the weak r-process elements are tend to be produced most efficiently for this range of $Y_{\mathrm{e}}$. We note that the exact processes complicatedly depend on entropy, $Y_{\mathrm{e}}$, the properties of nuclear states, and the mass fraction of $\alpha$ particles during $\alpha$-rich freezeout.

The abundance peaks seem to locate at $Y_{\mathrm{e}} \sim 0.43$ for the normal energy models (1301 and 2501), and $Y_{\mathrm{e}} \sim 0.45-0.46$ for model-2520. It is interesting that the peak is located at a larger value of $Y_{\mathrm{e}}$ for the higher energy model. The reason for this is not simple because the yields depend on the complicated properties of nuclear structures. For example, in the $Y_{\mathrm{e}}=0.40$ case in Figure 8 (model-2520), the synthesized amounts of the weak r-process elements are small, but lighter elements, Ge to Kr, are quite abundant. For this specific case ${ }^{82} \mathrm{Ge}$, with $Y_{\mathrm{e}} \equiv \mathrm{Z} / \mathrm{A}=0.390$, is quite abundant after the explosive synthesis. This decays into ${ }^{82}$ Se and the synthesis of heavier weak r-process elements are suppressed.

\subsection{2. $M$ Dependence}

Since the density and temperature trajectories of the complete Si-burning region are not so different for model-1301 and model-2501, the abundance of weak r-process elements in model-1301 and model-2501 are similar (Figure 6, 7 and 9).

\subsubsection{E Dependence}

As seen in Figure 7, 8 and 9, high $E$ enhances the weak r-elements especially from $Y_{\mathrm{e}}=0.45$ to 0.47. Temperature of the complete Si-burning region in model-2520 is much higher than that in the model-2501. Therefore, an entropy of model2520 is much higher than that of model-2501, and 
much more $\alpha$-particles can be obtained in model2520 than in model-2501. This is why more Sr, Y and $\mathrm{Zr}$ are produced in model-2520 than in model2501.

The abundances of $\mathrm{Sr}, \mathrm{Y}$ and $\mathrm{Zr}$ are almost same in model-2501 and model-2520 when $Y_{\mathrm{e}}=0.49$ and 0.50 . When $Y_{\mathrm{e}}$ is 0.49 and 0.50 , the elements produced also have $Y_{\mathrm{e}} \simeq 0.5$. Since heavy nucleus with $Y_{\mathrm{e}} \simeq 0.5$ are less bound than those with neutron-rich (Hoffman et al. 1996), when $Y_{\mathrm{e}} \simeq 0.5$, heavier elements than $\mathrm{Zn}$ are not produced even though $E$ is high.

\subsection{Abundance Patterns of Whole Ejecta with Mass Ejection below $M_{\text {cut }}$}

Nucleosynthesis pattern in the complete Siburning region with constant $Y_{\mathrm{e}}$ is shown in the previous subsection. In this subsection, assuming various $Y_{\mathrm{e}}$ distributions in region below $M_{\text {cut }}$, we present abundance patterns of whole ejecta with mass ejection below $M_{\text {cut }}$. For the matter below $M_{\text {cut }}$, the yields are averaged for the $Y_{\mathrm{e}}$ values ranged from $Y_{\mathrm{e}}^{\min }$ to $Y_{\mathrm{e}}^{\max }$. For example, the $\mathrm{Y}_{\mathrm{e}}$ distribution $\mathrm{Y}_{\mathrm{e}}=0.45-0.50$ means that the yields are the average of the six models with $\mathrm{Y}_{\mathrm{e}}=0.45$, $0.46,0.47,0.48,0.49$ and 0.50 . In this subsection again we do not consider the matter with $Y_{\mathrm{e}}>0.5$.

The main parameters of our models are $\Delta M$ and $Y_{\mathrm{e}}^{\mathrm{min}} . \Delta M$ is the mass of the ejected matter from the region below $M_{\text {cut }}$, and $Y_{\mathrm{e}}^{\mathrm{min}}$ is the lowest $Y_{\mathrm{e}}$ of the ejected matter. $\Delta M$ of the matter below $M_{\text {cut }}$ is added to the matter above $M_{\text {cut }}$, and they are assumed to be ejected to the outer space all together. Small amounts of matter with low $Y_{\mathrm{e}}$ could be ejected in two-dimensional or jet-like explosion models (e.g., Janka et al. 2003). As shown in the previous subsection, large amounts of Sr, Y and $\mathrm{Zr}$ are obtained when $Y_{\mathrm{e}}=0.43$ in model-1301 and model-2501, and when $Y_{\mathrm{e}}=0.45$ in model2520. Therefore, we take $Y_{\mathrm{e}}^{\max }=0.5$, and $Y_{\mathrm{e}}^{\min }$ $=0.42$ and 0.43 for model-1301 and model-2501, and various values from $Y_{\mathrm{e}}^{\mathrm{min}}=0.45$ to 0.49 for model-2520. Here, $\Delta M$ is selected to obtain $0 \lesssim$ $[\mathrm{Zn} / \mathrm{Fe}] \lesssim 0.5$.

The abundance patterns of the ejected matter for model-1301, model-2501 and model-2520 are shown in Figure 10, 11 and 12-13, respectively. $Y_{\mathrm{e}}^{\mathrm{min}}$ and $\Delta M$ and some related numbers for models (a) are summarized in Table 2. In the models (a), $\Delta M$ is set to obtain $[\mathrm{Zn} / \mathrm{Fe}] \simeq 0.5$ for $Y_{\mathrm{e}}^{\mathrm{min}} \lesssim 0.46$. For $Y_{\mathrm{e}}^{\mathrm{min}} \gtrsim 0.47$ (model-2520), the same value of $\Delta M$ with the $Y_{\mathrm{e}}^{\mathrm{min}} \lesssim 0.46$ models is adopted because $[\mathrm{Zn} / \mathrm{Fe}]$ is lower than 0.5 even if all the matter below $M_{\text {cut }}$ is ejected. For the models (b) and (c), $\Delta M$ of the model (a) is divided by 3 and 10 , respectively.

As shown in Figure 10 and 11, [Sr,Y,Zr/Fe] are not improved to fit the observation in model-1301 and model-2501. On the contrary, [Sr,Y,Zr/Fe] in model-2520 are high enough to be ranged in $-1<[\mathrm{Sr}, \mathrm{Y}, \mathrm{Zr} / \mathrm{Fe}]<1$ when $Y_{\mathrm{e}}^{\mathrm{min}}$ is from 0.45 to 0.46 (Fig. 11). Note that the abundance patterns of $[\mathrm{Sr}, \mathrm{Y}, \mathrm{Zr} / \mathrm{Fe}]$ are different depending on $Y_{\mathrm{e}}^{\mathrm{min}}$. When $Y_{\mathrm{e}}^{\mathrm{min}}=0.45$, those ratios have the relation of $[\mathrm{Sr} / \mathrm{Fe}] \sim[\mathrm{Zr} / \mathrm{Fe}]>[\mathrm{Y} / \mathrm{Fe}]$. When $Y_{\mathrm{e}}^{\mathrm{min}}=0.452$, $[\mathrm{Sr} / \mathrm{Fe}] \simeq[\mathrm{Y} / \mathrm{Fe}]<[\mathrm{Zr} / \mathrm{Fe}]$. When $Y_{\mathrm{e}}^{\mathrm{min}}=0.454-$ $0.46,[\mathrm{Sr} / \mathrm{Fe}]<[\mathrm{Y} / \mathrm{Fe}]<[\mathrm{Zr} / \mathrm{Fe}]$.

\subsection{Comparisons with Individual EMP Star}

In this subsection we compare our yields of model-2520 with abundance patterns of EMP stars. Among the 22 weak r-process stars mentioned in $\S 1,15$ stars have $[\mathrm{Sr} / \mathrm{Ba}]>1$ and $[\mathrm{Y} / \mathrm{Eu}]>1$. We select $\mathrm{Sr}$-rich stars with $[\mathrm{Sr} / \mathrm{Ba}]$ $>1,[\mathrm{Y} / \mathrm{Eu}]>1$ and $[\mathrm{Sr} / \mathrm{Fe}]>0$ : BS16477$003([\mathrm{Fe} / \mathrm{H}]=-3.36), \mathrm{CS} 22873-166([\mathrm{Fe} / \mathrm{H}]=-2.97)$ , CS22897-008 $([\mathrm{Fe} / \mathrm{H}]=-3.41)$ and $\mathrm{CS} 29518-051$ $([\mathrm{Fe} / \mathrm{H}]=-2.78)$. The observational data from He to $\mathrm{Zn}$ and beyond $\mathrm{Zn}$ are taken from Cayrel et al. (2004) and Francois et al. (2007), respectively. $Y_{\mathrm{e}}$ distribution and $\Delta M$ have been chosen in order to obtain the best fit to the observed abundances of Sr, Y and Zr. In order to adjust light to heavy element ratios, such as $\mathrm{O} / \mathrm{Fe}$, we also assume the following mixing-fallback process to take place in HN model-2520 (see e.g., Tominaga et al. 2007 for detail):

1. Burned material below $M_{\text {mix }}$ (out) is uniformly mixed.

2. Afterward only a fraction $(f)$ of the mixed material is ejected with the matter above $M_{\text {mix }}$ (out). We set $M_{\text {mix }}$ (out) $=3.60 M_{\odot}$ for the $\mathrm{C}$-poor stars with $[\mathrm{C} / \mathrm{Mg}]<0$, such as CS22873-166 and CS29518-051, and 5.76M $M_{\odot}$ for C-normal stars with $[\mathrm{C} / \mathrm{Mg}] \sim 0$, such as BS16477-003 and CS22897008. $M_{r}=3.60 M_{\odot}$ is a point above which $\mathrm{X}(\mathrm{Ca})<\mathrm{X}(\mathrm{Mg})$, and $M_{r}=5.76 M_{\odot}$ is a point in the O-rich layer. $Y_{\mathrm{e}}^{\mathrm{min}}, \Delta M, f, M_{\operatorname{mix}}$ (out) and the 
other values for each comparison are summarized in Table 3. Figure 14 shows comparisons between the yields of our mixing-fallback models and the abundance patterns of EMP stars. In addition to the abundance ratios of the elements heavier than $\mathrm{Si},[\mathrm{C} / \mathrm{Fe}],[\mathrm{Mg} / \mathrm{Fe}]$ and $[\mathrm{Al} / \mathrm{Fe}]$ show reasonable agreements with the observations. The nucleosynthesis yields in the ejecta for selected isotopes at the time around 150 seconds after the explosion are also given in Tables 4 to 7 . To obtain these tables, the isotopes with their half-lives less than 30 days except ${ }^{56} \mathrm{Ni}$ are radioactively decayed.

\section{CONCLUSIONS AND DISCUSSIONS}

In this paper we assume uncertainty of $Y_{\mathrm{e}}$ in the deep regions below $M_{\text {cut }}$ and mass ejection from the regions for three models model-1301, model2501 and model-2520. Among those models, we obtain high [Sr,Y, $\mathrm{Zr} / \mathrm{Fe}]$ (ranged from -1 to 1) only in the model-2520. The "hypernova" model-2520 can reproduce the observational data of $\mathrm{Sr}, \mathrm{Y}$ and $\mathrm{Zr}$ in addition to the elements from $\mathrm{C}$ to $\mathrm{Zn}$.

We also find that the weak r-process elements are not contained in the "normal" supernova models $1301 \& 2501$, even though low $Y_{\mathrm{e}}(\gtrsim 0.40)$ matter is ejected. In the normal supernova models, however, intermediate mass elements from Ga to Rb may be abundantly ejected (Figure 10 and 11). It is interesting to note that there have been no observational evidences that Ga-Rb-rich stars exist in EMP stars. It is possible that normal SNe do not eject sufficient amounts of low $Y_{\mathrm{e}}$ matter or that we have observationally overlooked such Ga-Rb-rich stars.

In comparisons with 4 EMP stars in Figure 14, the ratios of some elements, i.e., $[\mathrm{Na} / \mathrm{Fe}],[\mathrm{K} / \mathrm{Fe}]$, $[\mathrm{Sc} / \mathrm{Fe}],[\mathrm{Mn} / \mathrm{Fe}]$ and $[\mathrm{Co} / \mathrm{Fe}]$ show deficiencies from the observation as our previous finding (see e.g., UN05; Tominaga et al. 2007). In Tominaga et al. (2007), possible solutions are discussed as follows: $\mathrm{Na}$ is mostly synthesized in the C-shell burning, and the produced amount of $\mathrm{Na}$ depends on the overshooting at the edge of the convective C-burning shell (Iwamoto et al. 2005). Since no overshooting is included in the present presupernova evolution models, the inclusion of the overshooting could enhance the $\mathrm{Na}$ abundance. $[\mathrm{K} / \mathrm{Fe}]$ is slightly enhanced by the "low-density" modification (UN05; Tominaga et al. 2007) and
Iwamoto et al. (2006) suggests that the matter with large $Y_{\mathrm{e}}(>0.5)$ can produce enough $\mathrm{K}$. $[\mathrm{Sc} / \mathrm{Fe}]$ and $[\mathrm{Ti} / \mathrm{Fe}]$ can be enhanced by nucleosynthesis in high-entropy environments (a low-density modification, UN05; Tominaga et al. 2007) or in a jet-like explosion (Nagataki et al. 2003; Maeda \& Nomoto 2003; Tominaga 2009), and further an enhancement of $[\mathrm{Sc} / \mathrm{Fe}]$ can be realized if $Y_{\mathrm{e}}$ (>0.5) (Pruet et al. 2004a, 2005; Fröhlich et al. 2006b; Iwamoto et al. 2006). [Co/Fe] and [Mn/Fe] can be improved by the $Y_{\mathrm{e}}$ modification in the Si-burning region (UN05; Tominaga et al. 2007) and $[\mathrm{Mn} / \mathrm{Fe}]$ can also be enhanced by a neutrino process (Woosley \& Weaver 1995; Yoshida et al. 2008).

Many of the solutions discussed above include the the ejection of proton-rich $\left(Y_{\mathrm{e}}>0.5\right)$ "complete Si-burning" matter. This does not contradict with our assumption that the neutron-rich $\left(Y_{\mathrm{e}}<0.5\right)$ "complete Si-burning" matter is ejected. This is because both $Y_{\mathrm{e}}>0.5$ matter and $Y_{\mathrm{e}}<0.5$ matter could be ejected simultaneously from the "hotbubble region" in the multi-dimensional simulations (e.g., Janka et al. 2003; Pruet et al. 2005). Although we do not include the proton-rich matter, the inclusion of the matter does not change the present results because the contributions from the proton-rich matter can merely be added to the present results. The nucleosynthesis in the protonrich matter as well as the neutrino process will be considered elsewhere.

There also remains a possible problem in elements Mo, Ru and Rh. The observational data of those elements is obtained in only two EMP stars HD122563 and HD88609 (see Honda et al. 2007). The abundance patterns of them show continuously decreasing trends compared with the main r-process as a function of atomic number, from $\mathrm{Sr}$ to $\mathrm{Yb}(\mathrm{Z}=38-70)$. Our models have $[\mathrm{Mo} / \mathrm{Fe}] \sim$ $-5, \quad[\mathrm{Ru} / \mathrm{Fe}] \sim-2$ and $[\mathrm{Rh} / \mathrm{Fe}] \sim-3$, while $\mathrm{HD} 122563$ has $[\mathrm{Mo} / \mathrm{Fe}]=-0.02,[\mathrm{Ru} / \mathrm{Fe}]=0.07$ and $[\mathrm{Rh} / \mathrm{Fe}]<0.45$, and HD88609 has $[\mathrm{Mo} / \mathrm{Fe}]=0.15$, $[\mathrm{Ru} / \mathrm{Fe}]=0.32$ and $[\mathrm{Rh} / \mathrm{Fe}]<0.70$. Further observation will be needed to investigate whether high ratios of $\mathrm{Mo}, \mathrm{Ru}$ and $\mathrm{Rh}$ are typical in the weak r-process stars. Since there two stars are relatively metal rich, $[\mathrm{Fe} / \mathrm{H}] \sim-3.0(\mathrm{HD} 88609)$ and $[\mathrm{Fe} / \mathrm{H}]$ $\sim-2.7$ (HD122563), their abundance patterns may be contaminated by several SNe, r-process and s-process. 
There may be a solution in a high-entropy matter ejection. Pruet et al. (2006) investigated the contribution of the proton-rich high-entropy winds using the two-dimensional $15 M_{\odot}$ core collapse model of Janka et al. (2003). The origin of the so-called p-process nuclei from $\mathrm{A}=92$ to 126 is an unsolved riddles of nuclear astrophysics, but they found synthesis of p-rich nuclei up to ${ }^{102} \mathrm{Pd}$ in the proton-rich wind, although their calculations do not show an efficient production of ${ }^{92} \mathrm{Mo}$. $Y_{\mathrm{e}}$ of proton-rich neutrino wind in Pruet et al. (2006) is ranged from 0.539 to 0.558 , and entropy $\left(s / k_{b}\right)$ is from 54.8 to 76.9 . The entropy in the supernova shock model $\left(s / k_{b} \lesssim 15\right)$ is much smaller. Since the properties of the neutrino driven wind is uncertain, the nucleosynthesis in the proton-rich wind is certainly interesting, especially if there are no other possibilities.

The $Y_{\mathrm{e}}$ below the mass cut is very sensitive to the rates for the neutrino and positron captures on neutrons and for the inverse captures on protons. Unfortunately the actual amount of neutrino flux depends on the unknown explosion mechanisms. Therefore, the $Y_{\mathrm{e}}$ of ejecta for a specific model needs to be calculated in the future works.

In Figure 15 we show [Sr/Fe] vs. [Zn/Fe] because $[\mathrm{Zn} / \mathrm{Fe}]$ is a rough barometer of the SN explosion energy (e.g., UN02, UN05). The implications obtained from this figure are as follows. We have shown that the weak r-process elements can be produced without introducing extra higherentropy matter in high $E \mathrm{SN}$ models. Previous work (UN02) suggests that the abundance of EMP stars with high $[\mathrm{Zn} / \mathrm{Fe}]$ are reproduced by high $E$ SN models. The apparent no-correlation between $[\mathrm{Sr} / \mathrm{Fe}]$ and $[\mathrm{Zn} / \mathrm{Fe}]$ means that, if our interpretation is correct, only a portion of HNe eject a large amount of $\mathrm{Sr}$ but the rest of $\mathrm{HNe}$ eject a small amount of Sr. In other words high $E$ is just a necessary condition to eject the weak r-process elements and other factors determine the ejected mass of the weak r-process elements.

Our results show that normal $E$ models do not produce large amount of $\mathrm{Sr}, \mathrm{Y}$, and $\mathrm{Zr}$. However we should note that this is not the case if a normal SN ejects somehow higher-entropy matter than the supernova shock. Figure 15 does not deny such a possibility because $[\mathrm{Zn} / \mathrm{Fe}] \sim 0$ stars may be reproduced by a normal $\mathrm{SNe}$ or the mixture of several SNe (Tominaga et al. 2007). This figure show that all $[\mathrm{Zn} / \mathrm{Fe}] \sim 0$ stars show high $[\mathrm{Sr} / \mathrm{Fe}]$. A possible interpretation is that the actual normal SNe can produce $[\mathrm{Sr} / \mathrm{Fe}] \sim 0$. If this is the case, our results imply that a normal $\mathrm{SN}$ can be ejecting a higher entropy matter than the supernova shock, that is likely the neutrino driven wind. This fact may be used to constrain the neutrino driven wind of a normal SN, though we have to handle the $Y_{\mathrm{e}}>0.5$ matter before qualitatively constraining the model, because the high-entropy proton-rich matter may also produce the weak r-process elements as shown in Pruet et al. (2006).

We would like to thank T. Yoshida, W. Aoki and S. Wanajo for useful comments and discussions. This work has been supported in part by the grants-in-aid for Scientific Research (19840010) from the MEXT of Japan.

\section{REFERENCES}

Anders, E. \& Grevesse, N. 1989, GeCoA, 53, 197

Aoki, W. et al. 2005, ApJ, 632, 611

Blinnikov, S., Lundqvist, P., Bartunov, O., Nomoto, K., Iwamoto, K. 2000, ApJ, 532, 1132

Cayrel, R. et al. 2004, A\&A, 416, 1117

Chieffi, A. \& Limongi, M. 2002, ApJ, 577, 281

Francois, P. et al. 2007, A\&A, 476, 935

Frölich, C. et al. 2006a, ApJ, 637, 415

Fröhlich, C. et al. 2006b, Phys. Rev. Lett., 96, 142502

Heger, A. \& Woosley, S.E. 2002, ApJ, 567, 532

Heger, A. \& Woosley, S.E. 2008, ApJ Submitted

Hill, V. et al. 2002, A\&A, 387, 560

Hoffman, R. D., Woosley, S. E., Fuller, G. M., Meyer, B. S. 1996, ApJ, 460, 478

Honda, S., Aoki, W., Ishimaru, Y., Wanajo, S., \& Ryan, S. G. 2006, ApJ, 643, 1180

Honda, S., Aoki, W., Ishimaru, Y., Wanajo, S. 2007, ApJ, 666, 1189

Iwamoto, N., Umeda, H., Tominaga, N., Nomoto, K., Maeda, K. 2005, Science, 309, 451 
Iwamoto, N., Umeda, H., Nomoto, K., Tominaga, N., Thielemann, F., Hix, W. 2006, AIPC, 847, 409

Janka, H.-Th., Buras, R., Rampp, M. 2003, NuPhA., 718, 269

Liebendörfer, M., et al. 2003, Nucl. Phys., A719, 144

Maeda, K., \& Nomoto, K. 2003, ApJ, 598, 1163

Nagataki, S., Mizuta, A., Yamada, S., Takabe, H., \& Sato, K. 2003, ApJ, 596, 401

Nomoto, K., Maeda, K., Umeda, H., Ohkubo, T., Deng, J., \& Mazzali, P.A. 2003a, in IAU Symp 212, A massive Star Odyssey, from Main Sequence to Supernova, eds. V.D. Hucht, A. Herrero and C. Esteban(San Francisco: ASP), 395(astro-ph/0209064)

Nomoto, K., Umeda, H., Maeda, K., Ohkubo, T., Deng, J., \& Mazzali, P.A. 2003b, Nucl. Phys., A718, 277

Popham, R., Woosley, S. E., Fryer, C. 1999, ApJ, 518,356

Pruet, J., Woosley, S. E., Hoffman, R. D. 2003, ApJ, 586, 1254

Pruet, J., Surman, R., \& McLaughlin, G. C. 2004a, ApJ, 602, 101

Pruet, J., Woosley, S. E., Buras, R., Janka, H.-T., Hoffman, R. D. 2005, ApJ, 623, 325

Pruet, J., Hoffman, R.,D., Woosley, S. E., Janka, H.-T., Buras, R. 2006, ApJ, 644, 1028

Qian, Y.-Z., Woosley, S. E. 1996, ApJ, 471,331

Sneden, C., Cowan, J. J., Ivans, I. I., Fuller, G. M., Burles, S., Beers, T. C., \& Lawer, J. E. 2000, ApJ, 533, L139

Sneden, C., et al. 2003, ApJ, 591, 936

Tominaga, N., Umeda, H., \& Nomoto, K. 2007, ApJ, 660, 516

Tominaga 2009, ApJ in press (arXiv:0711.4815)

Travaglio, C., Gallino, R., Arnone, E., Cowan, J., Jordan, F., Sneden, C. 2004, ApJ, 601, 864
Truran, J. W., Cowan J. J., Pilachowski, C. A., Sneden, C. 2002, PASP, 114, 1293

Umeda, H., Nomoto, K., \& Nakamura, T., 2000, in The First Stars, ed. A. Weiss, T. Abel, \& V. Hill(Berlin: Springer), 150(astro-ph/9912248) (UNN00)

Umeda, H., \& Nomoto, K. 2002, ApJ, 565, 385 (UN02)

Umeda, H., \& Nomoto, K. 2003, Nature, 422, 871 (UN03)

Umeda, H., \& Nomoto, K. 2005, ApJ, 619, 427 (UN05)

Wanajo, S., \& Iahimaru, Y. 2006, in ISNA Conf., Nuclei in the Cosmos-IX.25-30 (CERN), 191

Wanajo, S., Kajino, T., Mathews, G. J., Otsuki, K. 2001, ApJ, 554, 578

Woosley, S. E. \& Hoffman, R. D. 1992, BAAS, 24, 1292

Woosley, S. E. \& Weaver, T. A. 1995, ApJS, 101, 181

Yoshida, T., Umeda, H., Nomoto, K. 2008, ApJ, 672,1043

This 2-column preprint was prepared with the AAS LATEX macros v5.2. 
TABLE 1

ISOTOPES INCLUDED IN THE NUCLEAR REACTION NETWORK

\begin{tabular}{llcc}
\hline \hline Isotope & \multicolumn{1}{c}{$\mathrm{A}$} & Isotope & $\mathrm{A}$ \\
\hline $\mathrm{n}$ & 1 & $\mathrm{~V}$ & $44-60$ \\
$\mathrm{H}$ & $1-3$ & $\mathrm{Cr}$ & $46-63$ \\
$\mathrm{He}$ & $3-4$ & $\mathrm{Mn}$ & $48-65$ \\
$\mathrm{Li}$ & $6-7$ & $\mathrm{Fe}$ & $50-68$ \\
$\mathrm{Be}$ & $7-9$ & $\mathrm{Co}$ & $51-71$ \\
$\mathrm{~B}$ & $8-13$ & $\mathrm{Ni}$ & $54-73$ \\
$\mathrm{C}$ & $11-15$ & $\mathrm{Cu}$ & $56-76$ \\
$\mathrm{~N}$ & $13-18$ & $\mathrm{Zn}$ & $59-78$ \\
$\mathrm{O}$ & $14-21$ & $\mathrm{Ga}$ & $60-81$ \\
$\mathrm{~F}$ & $17-23$ & $\mathrm{Ge}$ & $59-84$ \\
$\mathrm{Ne}$ & $18-26$ & $\mathrm{As}$ & $64-86$ \\
$\mathrm{Na}$ & $21-28$ & $\mathrm{Se}$ & $65-89$ \\
$\mathrm{Mg}$ & $22-31$ & $\mathrm{Br}$ & $68-92$ \\
$\mathrm{Al}$ & $25-34$ & $\mathrm{Kr}$ & $66-94$ \\
$\mathrm{Si}$ & $26-36$ & $\mathrm{Rb}$ & $72-97$ \\
$\mathrm{P}$ & $27-39$ & $\mathrm{Sr}$ & $69-100$ \\
$\mathrm{~S}$ & $30-42$ & $\mathrm{Y}$ & $76-102$ \\
$\mathrm{Cl}$ & $32-44$ & $\mathrm{Zr}$ & $74-105$ \\
$\mathrm{Ar}$ & $34-47$ & $\mathrm{Nb}$ & $80-107$ \\
$\mathrm{~K}$ & $36-50$ & $\mathrm{Mo}$ & $79-110$ \\
$\mathrm{Ca}$ & $38-52$ & $\mathrm{Tc}$ & $85-113$ \\
$\mathrm{Sc}$ & $40-55$ & $\mathrm{Ru}$ & $84-115$ \\
$\mathrm{Ti}$ & $42-57$ & $\mathrm{Rh}$ & $89-118$ \\
& & $\mathrm{Pd}$ & $89-121$ \\
\hline
\end{tabular}


TABle 2

\begin{tabular}{|c|c|c|c|c|c|c|c|c|c|}
\hline model & $Y_{\mathrm{e}}^{\min }$ & $\Delta M$ & {$[\mathrm{Sr} / \mathrm{Fe}]$} & {$[\mathrm{Y} / \mathrm{Fe}]$} & {$[\mathrm{Zr} / \mathrm{Fe}]$} & $M(\mathrm{Sr})$ & $M(\mathrm{Y})$ & $M(\mathrm{Zr})$ & $M\left({ }^{56} \mathrm{Ni}\right)$ \\
\hline $1301(\mathrm{a})$ & 0.42 & $1.65 \mathrm{E}-03$ & -2.38 & -3.38 & -3.20 & $1.02 \mathrm{E}-08$ & $2.10 \mathrm{E}-10$ & $8.02 \mathrm{E}-10$ & $5.93 \mathrm{E}-02$ \\
\hline 1301(a) & 0.43 & $1.65 \mathrm{E}-03$ & -2.37 & -3.47 & -3.25 & $1.05 \mathrm{E}-08$ & $1.69 \mathrm{E}-10$ & $7.16 \mathrm{E}-10$ & $5.93 \mathrm{E}-02$ \\
\hline $2501(\mathrm{a})$ & 0.42 & $2.02 \mathrm{E}-02$ & -1.99 & -3.18 & -3.12 & $9.12 \mathrm{E}-08$ & $1.21 \mathrm{E}-09$ & $3.55 \mathrm{E}-09$ & $2.19 \mathrm{E}-01$ \\
\hline 2501(a) & 0.43 & $2.02 \mathrm{E}-02$ & -1.99 & -3.33 & -3.20 & $9.26 \mathrm{E}-08$ & $8.62 \mathrm{E}-10$ & $2.92 \mathrm{E}-09$ & $2.19 \mathrm{E}-01$ \\
\hline $2520(\mathrm{a})$ & 0.45 & $1.08 \mathrm{E}-02$ & 0.54 & 0.22 & 0.43 & $6.56 \mathrm{E}-05$ & $6.40 \mathrm{E}-06$ & $2.59 \mathrm{E}-05$ & $4.60 \mathrm{E}-01$ \\
\hline 2520 (a) & 0.452 & $1.08 \mathrm{E}-02$ & 0.38 & 0.36 & 0.52 & $4.51 \mathrm{E}-05$ & $8.70 \mathrm{E}-06$ & $3.20 \mathrm{E}-05$ & $4.60 \mathrm{E}-01$ \\
\hline $2520(\mathrm{a})$ & 0.454 & $1.08 \mathrm{E}-02$ & 0.15 & 0.35 & 0.60 & $2.65 \mathrm{E}-05$ & $8.53 \mathrm{E}-06$ & $3.68 \mathrm{E}-05$ & $4.60 \mathrm{E}-01$ \\
\hline 2520 (a) & 0.456 & $1.08 \mathrm{E}-02$ & -0.11 & 0.26 & 0.65 & $1.47 \mathrm{E}-05$ & $7.00 \mathrm{E}-06$ & $4.28 \mathrm{E}-05$ & $4.60 \mathrm{E}-01$ \\
\hline 2520(a) & 0.458 & $1.08 \mathrm{E}-02$ & -0.33 & 0.15 & 0.66 & 8.73E-06 & $5.47 \mathrm{E}-06$ & $4.44 \mathrm{E}-05$ & $4.60 \mathrm{E}-01$ \\
\hline $2520(\mathrm{a})$ & 0.46 & $1.08 \mathrm{E}-02$ & -0.72 & -0.17 & 0.46 & $3.57 \mathrm{E}-06$ & $2.61 \mathrm{E}-06$ & $2.77 \mathrm{E}-05$ & $4.61 \mathrm{E}-01$ \\
\hline $2520(\mathrm{a})$ & 0.47 & $1.08 \mathrm{E}-02$ & -2.24 & -2.32 & -0.51 & $1.07 \mathrm{E}-07$ & $1.84 \mathrm{E}-08$ & $2.98 \mathrm{E}-06$ & 4.61E-01 \\
\hline 2520 (a) & 0.48 & $1.08 \mathrm{E}-02$ & -3.41 & -4.13 & -3.37 & 7.32E-09 & $2.84 \mathrm{E}-10$ & $4.09 \mathrm{E}-09$ & $4.62 \mathrm{E}-01$ \\
\hline 2520 (a) & 0.49 & $1.08 \mathrm{E}-02$ & -3.67 & -4.51 & -3.67 & 4.01E-09 & $1.20 \mathrm{E}-10$ & 2.07E-09 & $4.64 \mathrm{E}-01$ \\
\hline
\end{tabular}

Note.-Each column shows model name, $Y_{\mathrm{e}}^{\mathrm{min}}, \Delta M,[\mathrm{Sr} / \mathrm{Fe}],[\mathrm{Y} / \mathrm{Fe}],[\mathrm{Zr} / \mathrm{Fe}]$ and ejected masses of Sr, Y, Zr and ${ }^{56} \mathrm{Ni}$ for the models (a) in the Figures $10-13$. In the models (a), $\Delta M$ is set to obtain $[\mathrm{Zn} / \mathrm{Fe}] \simeq 0.5$ for $Y_{\mathrm{e}}^{\mathrm{min}} \lesssim 0.46$. For $Y_{\mathrm{e}}^{\mathrm{min}}>0.47$ (model-2520), the same value of $\Delta M$ with the $Y_{\mathrm{e}}^{\mathrm{min}} \lesssim 0.46$ models is adopted because [Zn/Fe] is lower than 0.5 even if all the matter below $M_{\text {cut }}$ is ejected. 
TABLE 3

\begin{tabular}{clcccccccc}
\hline \hline model & $Y_{\mathrm{e}}^{\min }$ & $f \times \Delta M$ & $f$ & $M_{\text {mix }}($ out $)$ & $M(\mathrm{Sr})$ & $M(\mathrm{Y})$ & $M(\mathrm{Zr})$ & $M\left({ }^{56} \mathrm{Ni}\right)$ & star \\
\hline $2520-1$ & 0.452 & $2.70 \mathrm{E}-04$ & 0.05 & 5.76 & $1.13 \mathrm{E}-06$ & $2.17 \mathrm{E}-07$ & $8.00 \mathrm{E}-07$ & $2.30 \mathrm{E}-02$ & BS16477-003 \\
$2520-2$ & 0.45 & $5.90 \mathrm{E}-04$ & 0.05 & 5.76 & $3.61 \mathrm{E}-06$ & $3.52 \mathrm{E}-07$ & $1.43 \mathrm{E}-06$ & $2.30 \mathrm{E}-02$ & CS22897-008 \\
$2520-3$ & 0.45 & $1.08 \mathrm{E}-03$ & 0.20 & 3.60 & $6.56 \mathrm{E}-06$ & $6.40 \mathrm{E}-07$ & $2.60 \mathrm{E}-06$ & $9.19 \mathrm{E}-02$ & CS22873-166 \\
$2520-4$ & 0.45 & $1.35 \mathrm{E}-03$ & 0.25 & 3.60 & $8.19 \mathrm{E}-06$ & $8.00 \mathrm{E}-07$ & $3.24 \mathrm{E}-06$ & $1.15 \mathrm{E}-01$ & CS29518-051 \\
\hline
\end{tabular}

Note.-The numbers shown are model, $Y_{\mathrm{e}}^{\mathrm{min}}, f \times \Delta M, f, M_{\text {mix }}$ (out), $M(\mathrm{Sr}), M(\mathrm{Y}), M(\mathrm{Zr}), M\left({ }^{56} \mathrm{Ni}\right)$ and star names for the models in Figure 14. The masses are in the units of $M_{\odot}$. In our definition $f \times \Delta M$ is the actual ejected mass coming from the below the mass-cut. 
TABLE 4

YIELDS (IN $\left.M_{\odot}\right)$ FOR THE MODEL 2520-1

\begin{tabular}{|c|c|c|c|c|c|c|c|}
\hline Isotope & mass & Isotope & mass & Isotope & mass & Isotope & mass \\
\hline${ }^{12} \mathrm{C}$ & $1.755 \mathrm{E}-01$ & ${ }^{46} \mathrm{Sc}$ & $4.216 \mathrm{E}-13$ & ${ }^{73} \mathrm{Ge}$ & $3.551 \mathrm{E}-10$ & ${ }^{92} \mathrm{Mo}$ & 4.850E-09 \\
\hline${ }^{13} \mathrm{C}$ & $5.045 \mathrm{E}-08$ & ${ }^{44} \mathrm{Ti}$ & $1.502 \mathrm{E}-05$ & ${ }^{74} \mathrm{Ge}$ & 8.559E-09 & ${ }^{93} \mathrm{Mo}$ & $9.053 \mathrm{E}-11$ \\
\hline${ }^{14} \mathrm{C}$ & $1.369 \mathrm{E}-10$ & ${ }^{46} \mathrm{Ti}$ & $2.482 \mathrm{E}-07$ & ${ }^{76} \mathrm{Ge}$ & $2.588 \mathrm{E}-12$ & ${ }^{94} \mathrm{Mo}$ & $2.144 \mathrm{E}-10$ \\
\hline${ }^{14} \mathrm{~N}$ & $6.300 \mathrm{E}-04$ & ${ }^{47} \mathrm{Ti}$ & $9.284 \mathrm{E}-07$ & ${ }^{73} \mathrm{As}$ & 4.569E-09 & ${ }^{95} \mathrm{Mo}$ & $5.496 \mathrm{E}-13$ \\
\hline${ }^{15} \mathrm{~N}$ & $4.046 \mathrm{E}-07$ & ${ }^{48} \mathrm{Ti}$ & $4.214 \mathrm{E}-05$ & ${ }^{75} \mathrm{As}$ & 3.377E-09 & ${ }^{96} \mathrm{Mo}$ & $9.662 \mathrm{E}-13$ \\
\hline${ }^{16} \mathrm{O}$ & $4.086 \mathrm{E}-01$ & ${ }^{49} \mathrm{Ti}$ & $3.174 \mathrm{E}-10$ & ${ }^{74} \mathrm{Se}$ & $3.920 \mathrm{E}-08$ & ${ }^{97} \mathrm{Mo}$ & $2.373 \mathrm{E}-13$ \\
\hline${ }^{17} \mathrm{O}$ & $1.478 \mathrm{E}-06$ & ${ }^{50} \mathrm{Ti}$ & $2.678 \mathrm{E}-07$ & ${ }^{75} \mathrm{Se}$ & $1.748 \mathrm{E}-09$ & ${ }^{98} \mathrm{Mo}$ & $9.873 \mathrm{E}-14$ \\
\hline${ }^{18} \mathrm{O}$ & $5.506 \mathrm{E}-07$ & ${ }^{49} \mathrm{~V}$ & $4.535 \mathrm{E}-07$ & ${ }^{76} \mathrm{Se}$ & $1.596 \mathrm{E}-07$ & ${ }^{100} \mathrm{Mo}$ & $6.059 \mathrm{E}-15$ \\
\hline${ }^{19} \mathrm{~F}$ & 8.379E-08 & ${ }^{50} \mathrm{~V}$ & $1.184 \mathrm{E}-11$ & ${ }^{77} \mathrm{Se}$ & $1.744 \mathrm{E}-09$ & ${ }^{95} \mathrm{Tc}$ & $8.480 \mathrm{E}-11$ \\
\hline${ }^{20} \mathrm{Ne}$ & $6.517 \mathrm{E}-02$ & ${ }^{51} \mathrm{~V}$ & $2.164 \mathrm{E}-06$ & ${ }^{78} \mathrm{Se}$ & $4.886 \mathrm{E}-08$ & ${ }^{97} \mathrm{Tc}$ & $5.534 \mathrm{E}-11$ \\
\hline${ }^{21} \mathrm{Ne}$ & $1.754 \mathrm{E}-06$ & ${ }^{50} \mathrm{Cr}$ & $4.088 \mathrm{E}-07$ & ${ }^{79} \mathrm{Se}$ & $7.851 \mathrm{E}-11$ & ${ }^{98} \mathrm{Tc}$ & $1.019 \mathrm{E}-13$ \\
\hline${ }^{22} \mathrm{Ne}$ & $7.150 \mathrm{E}-07$ & ${ }^{52} \mathrm{Cr}$ & $4.455 \mathrm{E}-04$ & ${ }^{80} \mathrm{Se}$ & $6.644 \mathrm{E}-10$ & ${ }^{99} \mathrm{Tc}$ & $7.414 \mathrm{E}-14$ \\
\hline${ }^{22} \mathrm{Na}$ & $1.287 \mathrm{E}-06$ & ${ }^{53} \mathrm{Cr}$ & $9.406 \mathrm{E}-08$ & ${ }^{82} \mathrm{Se}$ & $2.263 \mathrm{E}-13$ & ${ }^{96} \mathrm{Ru}$ & $2.458 \mathrm{E}-10$ \\
\hline${ }^{23} \mathrm{Na}$ & $1.496 \mathrm{E}-05$ & ${ }^{54} \mathrm{Cr}$ & $1.555 \mathrm{E}-06$ & ${ }^{79} \mathrm{Br}$ & $4.948 \mathrm{E}-09$ & ${ }^{98} \mathrm{Ru}$ & $1.099 \mathrm{E}-10$ \\
\hline${ }^{24} \mathrm{Mg}$ & $3.295 \mathrm{E}-02$ & ${ }^{53} \mathrm{Mn}$ & $1.134 \mathrm{E}-05$ & ${ }^{81} \mathrm{Br}$ & $2.286 \mathrm{E}-09$ & ${ }^{99} \mathrm{Ru}$ & $5.395 \mathrm{E}-11$ \\
\hline${ }^{25} \mathrm{Mg}$ & $8.304 \mathrm{E}-05$ & ${ }^{54} \mathrm{Mn}$ & $1.981 \mathrm{E}-09$ & ${ }^{78} \mathrm{Kr}$ & 9.330E-09 & ${ }^{100} \mathrm{Ru}$ & $3.006 \mathrm{E}-10$ \\
\hline${ }^{26} \mathrm{Mg}$ & $5.831 \mathrm{E}-06$ & ${ }^{55} \mathrm{Mn}$ & 3.709E-07 & ${ }^{80} \mathrm{Kr}$ & $2.412 \mathrm{E}-08$ & ${ }^{101} \mathrm{Ru}$ & $9.298 \mathrm{E}-14$ \\
\hline${ }^{26} \mathrm{Al}$ & $2.346 \mathrm{E}-06$ & ${ }^{54} \mathrm{Fe}$ & $4.782 \mathrm{E}-06$ & ${ }^{81} \mathrm{Kr}$ & $5.302 \mathrm{E}-10$ & ${ }^{102} \mathrm{Ru}$ & $5.723 \mathrm{E}-14$ \\
\hline${ }^{27} \mathrm{Al}$ & $2.605 \mathrm{E}-04$ & ${ }^{55} \mathrm{Fe}$ & $5.501 \mathrm{E}-06$ & ${ }^{82} \mathrm{Kr}$ & $3.516 \mathrm{E}-08$ & ${ }^{103} \mathrm{Ru}$ & $1.393 \mathrm{E}-13$ \\
\hline${ }^{28} \mathrm{Si}$ & $4.050 \mathrm{E}-02$ & ${ }^{56} \mathrm{Fe}$ & $5.754 \mathrm{E}-06$ & ${ }^{83} \mathrm{Kr}$ & $5.357 \mathrm{E}-10$ & ${ }^{104} \mathrm{Ru}$ & $2.455 \mathrm{E}-14$ \\
\hline${ }^{29} \mathrm{Si}$ & $9.614 \mathrm{E}-05$ & ${ }^{57} \mathrm{Fe}$ & 2.071E-07 & ${ }^{84} \mathrm{Kr}$ & $1.470 \mathrm{E}-08$ & ${ }^{106} \mathrm{Ru}$ & $1.458 \mathrm{E}-15$ \\
\hline${ }^{30} \mathrm{Si}$ & $3.956 \mathrm{E}-05$ & ${ }^{58} \mathrm{Fe}$ & $5.094 \mathrm{E}-06$ & ${ }^{85} \mathrm{Kr}$ & $3.664 \mathrm{E}-11$ & ${ }^{101} \mathrm{Rh}$ & $4.509 \mathrm{E}-11$ \\
\hline${ }^{32} \mathrm{Si}$ & $2.587 \mathrm{E}-13$ & ${ }^{59} \mathrm{Fe}$ & $8.189 \mathrm{E}-10$ & ${ }^{86} \mathrm{Kr}$ & $2.902 \mathrm{E}-10$ & ${ }^{102} \mathrm{Rh}$ & $2.008 \mathrm{E}-14$ \\
\hline${ }^{31} \mathrm{P}$ & $1.844 \mathrm{E}-05$ & ${ }^{60} \mathrm{Fe}$ & $7.672 \mathrm{E}-10$ & ${ }^{83} \mathrm{Rb}$ & 1.383E-09 & ${ }^{103} \mathrm{Rh}$ & $9.428 \mathrm{E}-12$ \\
\hline${ }^{32} \mathrm{~S}$ & $1.471 \mathrm{E}-02$ & ${ }^{56} \mathrm{Co}$ & $4.064 \mathrm{E}-08$ & ${ }^{84} \mathrm{Rb}$ & $1.082 \mathrm{E}-10$ & & \\
\hline${ }^{33} \mathrm{~S}$ & $1.725 \mathrm{E}-05$ & ${ }^{57} \mathrm{Co}$ & $3.451 \mathrm{E}-04$ & ${ }^{85} \mathrm{Rb}$ & $3.471 \mathrm{E}-09$ & & \\
\hline${ }^{34} \mathrm{~S}$ & $3.206 \mathrm{E}-06$ & ${ }^{58} \mathrm{Co}$ & $2.239 \mathrm{E}-09$ & ${ }^{87} \mathrm{Rb}$ & 8.623E-09 & & \\
\hline${ }^{35} \mathrm{~S}$ & $4.812 \mathrm{E}-11$ & ${ }^{59} \mathrm{Co}$ & $1.883 \mathrm{E}-07$ & ${ }^{84} \mathrm{Sr}$ & 1.239E-09 & & \\
\hline${ }^{36} \mathrm{~S}$ & $3.057 \mathrm{E}-12$ & ${ }^{60} \mathrm{Co}$ & $1.308 \mathrm{E}-09$ & ${ }^{85} \mathrm{Sr}$ & $1.931 \mathrm{E}-10$ & & \\
\hline${ }^{35} \mathrm{Cl}$ & $1.906 \mathrm{E}-06$ & ${ }^{56} \mathrm{Ni}$ & 2.297E-02 & ${ }^{86} \mathrm{Sr}$ & 3.750E-09 & & \\
\hline${ }^{36} \mathrm{Cl}$ & $1.244 \mathrm{E}-09$ & ${ }^{58} \mathrm{Ni}$ & $1.897 \mathrm{E}-04$ & ${ }^{87} \mathrm{Sr}$ & 1.490E-09 & & \\
\hline${ }^{37} \mathrm{Cl}$ & 1.131E-09 & ${ }^{59} \mathrm{Ni}$ & $5.428 \mathrm{E}-05$ & ${ }^{88} \mathrm{Sr}$ & $1.121 \mathrm{E}-06$ & & \\
\hline${ }^{36} \mathrm{Ar}$ & $2.644 \mathrm{E}-03$ & ${ }^{60} \mathrm{Ni}$ & $5.189 \mathrm{E}-04$ & ${ }^{89} \mathrm{Sr}$ & $3.053 \mathrm{E}-11$ & & \\
\hline${ }^{37} \mathrm{Ar}$ & 1.193E-06 & ${ }^{61} \mathrm{Ni}$ & $9.478 \mathrm{E}-06$ & ${ }^{90} \mathrm{Sr}$ & $9.241 \mathrm{E}-14$ & & \\
\hline${ }^{38} \mathrm{Ar}$ & $6.251 \mathrm{E}-07$ & ${ }^{62} \mathrm{Ni}$ & $4.693 \mathrm{E}-05$ & ${ }^{88} \mathrm{Y}$ & $7.221 \mathrm{E}-11$ & & \\
\hline${ }^{39} \mathrm{Ar}$ & $1.520 \mathrm{E}-12$ & ${ }^{63} \mathrm{Ni}$ & 2.101E-08 & ${ }^{89} \mathrm{Y}$ & $2.174 \mathrm{E}-07$ & & \\
\hline${ }^{40} \mathrm{Ar}$ & $7.346 \mathrm{E}-13$ & ${ }^{64} \mathrm{Ni}$ & $2.509 \mathrm{E}-07$ & ${ }^{91} \mathrm{Y}$ & $3.240 \mathrm{E}-13$ & & \\
\hline${ }^{42} \mathrm{Ar}$ & $3.761 \mathrm{E}-17$ & ${ }^{63} \mathrm{Cu}$ & $2.266 \mathrm{E}-06$ & ${ }^{88} \mathrm{Zr}$ & $2.081 \mathrm{E}-10$ & & \\
\hline${ }^{39} \mathrm{~K}$ & $6.151 \mathrm{E}-07$ & ${ }^{65} \mathrm{Cu}$ & $1.583 \mathrm{E}-07$ & ${ }^{90} \mathrm{Zr}$ & $7.952 \mathrm{E}-07$ & & \\
\hline${ }^{40} \mathrm{~K}$ & $3.358 \mathrm{E}-11$ & ${ }^{64} \mathrm{Zn}$ & $6.511 \mathrm{E}-05$ & ${ }^{91} \mathrm{Zr}$ & $9.083 \mathrm{E}-10$ & & \\
\hline${ }^{41} \mathrm{~K}$ & $1.288 \mathrm{E}-11$ & ${ }^{65} \mathrm{Zn}$ & $2.625 \mathrm{E}-07$ & $92 \mathrm{Zr}$ & $4.393 \mathrm{E}-11$ & & \\
\hline${ }^{40} \mathrm{Ca}$ & $2.605 \mathrm{E}-03$ & ${ }^{66} \mathrm{Zn}$ & $1.272 \mathrm{E}-05$ & ${ }^{93} \mathrm{Zr}$ & $4.954 \mathrm{E}-14$ & & \\
\hline${ }^{41} \mathrm{Ca}$ & $2.355 \mathrm{E}-07$ & ${ }^{67} \mathrm{Zn}$ & 7.894E-08 & ${ }^{94} \mathrm{Zr}$ & $2.988 \mathrm{E}-14$ & & \\
\hline${ }^{42} \mathrm{Ca}$ & $1.772 \mathrm{E}-08$ & ${ }^{68} \mathrm{Zn}$ & $3.639 \mathrm{E}-07$ & ${ }^{95} \mathrm{Zr}$ & $7.698 \mathrm{E}-14$ & & \\
\hline${ }^{43} \mathrm{Ca}$ & $1.459 \mathrm{E}-08$ & ${ }^{70} \mathrm{Zn}$ & $4.206 \mathrm{E}-11$ & ${ }^{96} \mathrm{Zr}$ & $1.295 \mathrm{E}-14$ & & \\
\hline${ }^{44} \mathrm{Ca}$ & $3.043 \mathrm{E}-11$ & ${ }^{69} \mathrm{Ga}$ & $5.433 \mathrm{E}-08$ & ${ }^{91} \mathrm{Nb}$ & $3.611 \mathrm{E}-09$ & & \\
\hline${ }^{45} \mathrm{Ca}$ & $3.966 \mathrm{E}-14$ & ${ }^{71} \mathrm{Ga}$ & $4.531 \mathrm{E}-09$ & ${ }^{92} \mathrm{Nb}$ & $1.732 \mathrm{E}-11$ & & \\
\hline${ }^{46} \mathrm{Ca}$ & $3.965 \mathrm{E}-12$ & ${ }^{68} \mathrm{Ge}$ & $1.131 \mathrm{E}-06$ & ${ }^{93} \mathrm{Nb}$ & $2.300 \mathrm{E}-12$ & & \\
\hline${ }^{48} \mathrm{Ca}$ & $2.440 \mathrm{E}-12$ & ${ }^{70} \mathrm{Ge}$ & $1.089 \mathrm{E}-06$ & ${ }^{94} \mathrm{Nb}$ & $6.665 \mathrm{E}-14$ & & \\
\hline${ }^{45} \mathrm{Sc}$ & $1.662 \mathrm{E}-08$ & ${ }^{72} \mathrm{Ge}$ & $4.058 \mathrm{E}-07$ & ${ }^{95} \mathrm{Nb}$ & $2.658 \mathrm{E}-13$ & & \\
\hline
\end{tabular}

Note.-Nucleosynthesis yields in the ejecta for the model 2520-1 (see Table 3 for the parameters of the model) evaluated at the time about 150 seconds after the explosion. To obtain this table, the isotopes with their half-lives less than 30 days (except ${ }^{56} \mathrm{Ni}$ ) are radioactively decayed. 
TABLE 5

YIELDS (IN $M_{\odot}$ ) FOR THE MODEL 2520-2

\begin{tabular}{|c|c|c|c|c|c|c|c|}
\hline Isotope & mass & Isotope & mass & Isotope & mass & Isotope & mass \\
\hline${ }^{12} \mathrm{C}$ & $1.755 \mathrm{E}-01$ & ${ }^{46} \mathrm{Sc}$ & $9.068 \mathrm{E}-13$ & ${ }^{73} \mathrm{Ge}$ & $1.385 \mathrm{E}-09$ & ${ }^{92} \mathrm{Mo}$ & $1.046 \mathrm{E}-08$ \\
\hline${ }^{13} \mathrm{C}$ & $5.045 \mathrm{E}-08$ & ${ }^{44} \mathrm{Ti}$ & $1.508 \mathrm{E}-05$ & ${ }^{74} \mathrm{Ge}$ & $6.408 \mathrm{E}-08$ & ${ }^{93} \mathrm{Mo}$ & $1.500 \mathrm{E}-10$ \\
\hline${ }^{14} \mathrm{C}$ & $1.369 \mathrm{E}-10$ & ${ }^{46} \mathrm{Ti}$ & $2.600 \mathrm{E}-07$ & ${ }^{76} \mathrm{Ge}$ & $9.684 \mathrm{E}-11$ & ${ }^{94} \mathrm{Mo}$ & $2.518 \mathrm{E}-10$ \\
\hline${ }^{14} \mathrm{~N}$ & $6.300 \mathrm{E}-04$ & ${ }^{47} \mathrm{Ti}$ & $9.410 \mathrm{E}-07$ & ${ }^{73} \mathrm{As}$ & $8.465 \mathrm{E}-09$ & ${ }^{95} \mathrm{Mo}$ & $6.159 \mathrm{E}-13$ \\
\hline${ }^{15} \mathrm{~N}$ & $4.046 \mathrm{E}-07$ & ${ }^{48} \mathrm{Ti}$ & $4.224 \mathrm{E}-05$ & ${ }^{75} \mathrm{As}$ & $1.002 \mathrm{E}-08$ & ${ }^{96} \mathrm{Mo}$ & $9.878 \mathrm{E}-13$ \\
\hline${ }^{16} \mathrm{O}$ & $4.086 \mathrm{E}-01$ & ${ }^{49} \mathrm{Ti}$ & $1.117 \mathrm{E}-09$ & ${ }^{74} \mathrm{Se}$ & $8.518 \mathrm{E}-08$ & ${ }^{97} \mathrm{Mo}$ & $2.383 \mathrm{E}-13$ \\
\hline${ }^{17} \mathrm{O}$ & $1.478 \mathrm{E}-06$ & ${ }^{50} \mathrm{Ti}$ & $1.168 \mathrm{E}-06$ & ${ }^{75} \mathrm{Se}$ & $3.689 \mathrm{E}-09$ & ${ }^{98} \mathrm{Mo}$ & $9.912 \mathrm{E}-14$ \\
\hline${ }^{18} \mathrm{O}$ & $5.506 \mathrm{E}-07$ & ${ }^{49} \mathrm{~V}$ & $4.614 \mathrm{E}-07$ & ${ }^{76} \mathrm{Se}$ & $2.947 \mathrm{E}-07$ & ${ }^{100} \mathrm{Mo}$ & $6.227 \mathrm{E}-15$ \\
\hline${ }^{19} \mathrm{~F}$ & $8.379 \mathrm{E}-08$ & ${ }^{50} \mathrm{~V}$ & $2.573 \mathrm{E}-11$ & ${ }^{77} \mathrm{Se}$ & $4.212 \mathrm{E}-09$ & ${ }^{95} \mathrm{Tc}$ & $8.516 \mathrm{E}-11$ \\
\hline${ }^{20} \mathrm{Ne}$ & $6.517 \mathrm{E}-02$ & ${ }^{51} \mathrm{~V}$ & $2.287 \mathrm{E}-06$ & ${ }^{78} \mathrm{Se}$ & $1.252 \mathrm{E}-07$ & ${ }^{97} \mathrm{Tc}$ & $5.567 \mathrm{E}-11$ \\
\hline${ }^{21} \mathrm{Ne}$ & $1.754 \mathrm{E}-06$ & ${ }^{50} \mathrm{Cr}$ & $4.174 \mathrm{E}-07$ & ${ }^{79} \mathrm{Se}$ & $4.423 \mathrm{E}-10$ & ${ }^{98} \mathrm{Tc}$ & $1.022 \mathrm{E}-13$ \\
\hline${ }^{22} \mathrm{Ne}$ & $7.150 \mathrm{E}-07$ & ${ }^{52} \mathrm{Cr}$ & $4.468 \mathrm{E}-04$ & ${ }^{80} \mathrm{Se}$ & 7.106E-09 & ${ }^{99} \mathrm{Tc}$ & $7.460 \mathrm{E}-14$ \\
\hline${ }^{22} \mathrm{Na}$ & $1.287 \mathrm{E}-06$ & ${ }^{53} \mathrm{Cr}$ & $2.320 \mathrm{E}-07$ & ${ }^{82} \mathrm{Se}$ & $1.243 \mathrm{E}-11$ & ${ }^{96} \mathrm{Ru}$ & $2.472 \mathrm{E}-10$ \\
\hline${ }^{23} \mathrm{Na}$ & $1.496 \mathrm{E}-05$ & ${ }^{54} \mathrm{Cr}$ & $5.295 \mathrm{E}-06$ & ${ }^{79} \mathrm{Br}$ & $8.292 \mathrm{E}-09$ & ${ }^{98} \mathrm{Ru}$ & $1.105 \mathrm{E}-10$ \\
\hline${ }^{24} \mathrm{Mg}$ & $3.295 \mathrm{E}-02$ & ${ }^{53} \mathrm{Mn}$ & $1.135 \mathrm{E}-05$ & ${ }^{81} \mathrm{Br}$ & 8.530E-09 & ${ }^{99} \mathrm{Ru}$ & $5.432 \mathrm{E}-11$ \\
\hline${ }^{25} \mathrm{Mg}$ & $8.304 \mathrm{E}-05$ & ${ }^{54} \mathrm{Mn}$ & $3.734 \mathrm{E}-09$ & ${ }^{78} \mathrm{Kr}$ & $1.820 \mathrm{E}-08$ & ${ }^{100} \mathrm{Ru}$ & $3.021 \mathrm{E}-10$ \\
\hline${ }^{26} \mathrm{Mg}$ & $5.831 \mathrm{E}-06$ & ${ }^{55} \mathrm{Mn}$ & $8.530 \mathrm{E}-07$ & ${ }^{80} \mathrm{Kr}$ & $5.220 \mathrm{E}-08$ & ${ }^{101} \mathrm{Ru}$ & $9.375 \mathrm{E}-14$ \\
\hline${ }^{26} \mathrm{Al}$ & $2.347 \mathrm{E}-06$ & ${ }^{54} \mathrm{Fe}$ & $4.860 \mathrm{E}-06$ & ${ }^{81} \mathrm{Kr}$ & $1.098 \mathrm{E}-09$ & ${ }^{102} \mathrm{Ru}$ & $5.789 \mathrm{E}-14$ \\
\hline${ }^{27} \mathrm{Al}$ & $2.605 \mathrm{E}-04$ & ${ }^{55} \mathrm{Fe}$ & $5.526 \mathrm{E}-06$ & ${ }^{82} \mathrm{Kr}$ & $6.539 \mathrm{E}-08$ & ${ }^{103} \mathrm{Ru}$ & $1.403 \mathrm{E}-13$ \\
\hline${ }^{28} \mathrm{Si}$ & $4.050 \mathrm{E}-02$ & ${ }^{56} \mathrm{Fe}$ & $1.081 \mathrm{E}-05$ & ${ }^{83} \mathrm{Kr}$ & $2.574 \mathrm{E}-09$ & ${ }^{104} \mathrm{Ru}$ & $2.507 \mathrm{E}-14$ \\
\hline${ }^{29} \mathrm{Si}$ & $9.614 \mathrm{E}-05$ & ${ }^{57} \mathrm{Fe}$ & $4.053 \mathrm{E}-07$ & ${ }^{84} \mathrm{Kr}$ & $4.073 \mathrm{E}-08$ & ${ }^{106} \mathrm{Ru}$ & $2.162 \mathrm{E}-15$ \\
\hline${ }^{30} \mathrm{Si}$ & $3.956 \mathrm{E}-05$ & ${ }^{58} \mathrm{Fe}$ & $1.482 \mathrm{E}-05$ & ${ }^{85} \mathrm{Kr}$ & $2.244 \mathrm{E}-10$ & ${ }^{101} \mathrm{Rh}$ & $4.534 \mathrm{E}-11$ \\
\hline${ }^{32} \mathrm{Si}$ & $2.758 \mathrm{E}-13$ & ${ }^{59} \mathrm{Fe}$ & $4.922 \mathrm{E}-09$ & ${ }^{86} \mathrm{Kr}$ & $3.441 \mathrm{E}-09$ & ${ }^{102} \mathrm{Rh}$ & $2.011 \mathrm{E}-14$ \\
\hline${ }^{31} \mathrm{P}$ & $1.844 \mathrm{E}-05$ & ${ }^{60} \mathrm{Fe}$ & 8.019E-09 & ${ }^{83} \mathrm{Rb}$ & $2.995 \mathrm{E}-09$ & ${ }^{103} \mathrm{Rh}$ & $9.514 \mathrm{E}-12$ \\
\hline${ }^{32} \mathrm{~S}$ & $1.471 \mathrm{E}-02$ & ${ }^{56} \mathrm{Co}$ & $4.292 \mathrm{E}-08$ & ${ }^{84} \mathrm{Rb}$ & $2.291 \mathrm{E}-10$ & & \\
\hline${ }^{33} \mathrm{~S}$ & $1.725 \mathrm{E}-05$ & ${ }^{57} \mathrm{Co}$ & $3.476 \mathrm{E}-04$ & ${ }^{85} \mathrm{Rb}$ & $6.494 \mathrm{E}-09$ & & \\
\hline${ }^{34} \mathrm{~S}$ & $3.210 \mathrm{E}-06$ & ${ }^{58} \mathrm{Co}$ & 4.357E-09 & ${ }^{87} \mathrm{Rb}$ & $2.652 \mathrm{E}-08$ & & \\
\hline${ }^{35} \mathrm{~S}$ & $4.816 \mathrm{E}-11$ & ${ }^{59} \mathrm{Co}$ & 3.613E-07 & ${ }^{84} \mathrm{Sr}$ & 2.651E-09 & & \\
\hline${ }^{36} \mathrm{~S}$ & $6.989 \mathrm{E}-12$ & ${ }^{60} \mathrm{Co}$ & 4.607E-09 & ${ }^{85} \mathrm{Sr}$ & $4.205 \mathrm{E}-10$ & & \\
\hline${ }^{35} \mathrm{Cl}$ & $1.913 \mathrm{E}-06$ & ${ }^{56} \mathrm{Ni}$ & $2.302 \mathrm{E}-02$ & ${ }^{86} \mathrm{Sr}$ & $6.693 \mathrm{E}-09$ & & \\
\hline${ }^{36} \mathrm{Cl}$ & $1.246 \mathrm{E}-09$ & ${ }^{58} \mathrm{Ni}$ & $2.436 \mathrm{E}-04$ & ${ }^{87} \mathrm{Sr}$ & $2.464 \mathrm{E}-09$ & & \\
\hline${ }^{37} \mathrm{Cl}$ & $1.132 \mathrm{E}-09$ & ${ }^{59} \mathrm{Ni}$ & $5.601 \mathrm{E}-05$ & ${ }^{88} \mathrm{Sr}$ & 3.593E-06 & & \\
\hline${ }^{36} \mathrm{Ar}$ & $2.644 \mathrm{E}-03$ & ${ }^{60} \mathrm{Ni}$ & $5.788 \mathrm{E}-04$ & ${ }^{89} \mathrm{Sr}$ & $2.271 \mathrm{E}-10$ & & \\
\hline${ }^{37} \mathrm{Ar}$ & $1.194 \mathrm{E}-06$ & ${ }^{61} \mathrm{Ni}$ & $1.067 \mathrm{E}-05$ & ${ }^{90} \mathrm{Sr}$ & $1.103 \mathrm{E}-12$ & & \\
\hline${ }^{38} \mathrm{Ar}$ & $6.295 \mathrm{E}-07$ & ${ }^{62} \mathrm{Ni}$ & $9.771 \mathrm{E}-05$ & ${ }^{88} \mathrm{Y}$ & $1.393 \mathrm{E}-10$ & & \\
\hline${ }^{39} \mathrm{Ar}$ & $2.135 \mathrm{E}-12$ & ${ }^{63} \mathrm{Ni}$ & $1.066 \mathrm{E}-07$ & ${ }^{89} \mathrm{Y}$ & $3.515 \mathrm{E}-07$ & & \\
\hline${ }^{40} \mathrm{Ar}$ & $1.633 \mathrm{E}-12$ & ${ }^{64} \mathrm{Ni}$ & $2.265 \mathrm{E}-06$ & ${ }^{91} \mathrm{Y}$ & $1.904 \mathrm{E}-12$ & & \\
\hline${ }^{42} \mathrm{Ar}$ & $1.188 \mathrm{E}-16$ & ${ }^{63} \mathrm{Cu}$ & $3.344 \mathrm{E}-06$ & ${ }^{88} \mathrm{Zr}$ & $3.741 \mathrm{E}-10$ & & \\
\hline${ }^{39} \mathrm{~K}$ & $6.229 \mathrm{E}-07$ & ${ }^{65} \mathrm{Cu}$ & $5.006 \mathrm{E}-07$ & ${ }^{90} \mathrm{Zr}$ & $1.418 \mathrm{E}-06$ & & \\
\hline${ }^{40} \mathrm{~K}$ & $3.891 \mathrm{E}-11$ & ${ }^{64} \mathrm{Zn}$ & $8.389 \mathrm{E}-05$ & ${ }^{91} \mathrm{Zr}$ & $1.582 \mathrm{E}-09$ & & \\
\hline${ }^{41} \mathrm{~K}$ & $2.182 \mathrm{E}-11$ & ${ }^{65} \mathrm{Zn}$ & $4.592 \mathrm{E}-07$ & ${ }^{92} \mathrm{Zr}$ & $1.178 \mathrm{E}-10$ & & \\
\hline${ }^{40} \mathrm{Ca}$ & $2.605 \mathrm{E}-03$ & ${ }^{66} \mathrm{Zn}$ & $2.364 \mathrm{E}-05$ & ${ }^{93} \mathrm{Zr}$ & $1.000 \mathrm{E}-13$ & & \\
\hline${ }^{41} \mathrm{Ca}$ & $2.359 \mathrm{E}-07$ & ${ }^{67} \mathrm{Zn}$ & $1.572 \mathrm{E}-07$ & ${ }^{94} \mathrm{Zr}$ & $3.159 \mathrm{E}-14$ & & \\
\hline${ }^{42} \mathrm{Ca}$ & $2.588 \mathrm{E}-08$ & ${ }^{68} \mathrm{Zn}$ & $1.622 \mathrm{E}-06$ & ${ }^{95} \mathrm{Zr}$ & $7.723 \mathrm{E}-14$ & & \\
\hline${ }^{43} \mathrm{Ca}$ & 1.619E-08 & ${ }^{70} \mathrm{Zn}$ & $9.605 \mathrm{E}-10$ & ${ }^{96} \mathrm{Zr}$ & $1.357 \mathrm{E}-14$ & & \\
\hline${ }^{44} \mathrm{Ca}$ & $6.262 \mathrm{E}-11$ & ${ }^{69} \mathrm{Ga}$ & $1.067 \mathrm{E}-07$ & ${ }^{91} \mathrm{Nb}$ & 7.695E-09 & & \\
\hline${ }^{45} \mathrm{Ca}$ & $1.711 \mathrm{E}-13$ & ${ }^{71} \mathrm{Ga}$ & $1.207 \mathrm{E}-08$ & ${ }^{92} \mathrm{Nb}$ & $3.452 \mathrm{E}-11$ & & \\
\hline${ }^{46} \mathrm{Ca}$ & $2.337 \mathrm{E}-11$ & ${ }^{68} \mathrm{Ge}$ & $1.900 \mathrm{E}-06$ & ${ }^{93} \mathrm{Nb}$ & $3.862 \mathrm{E}-12$ & & \\
\hline${ }^{48} \mathrm{Ca}$ & $1.134 \mathrm{E}-11$ & ${ }^{70} \mathrm{Ge}$ & $2.229 \mathrm{E}-06$ & ${ }^{94} \mathrm{Nb}$ & $6.996 \mathrm{E}-14$ & & \\
\hline${ }^{45} \mathrm{Sc}$ & $1.798 \mathrm{E}-08$ & ${ }^{72} \mathrm{Ge}$ & $8.084 \mathrm{E}-07$ & ${ }^{95} \mathrm{Nb}$ & $2.675 \mathrm{E}-13$ & & \\
\hline
\end{tabular}


TABLE 6

YIELDS (IN $\left.M_{\odot}\right)$ FOR THE MODEL 2520-3

\begin{tabular}{|c|c|c|c|c|c|c|c|}
\hline Isotope & mass & Isotope & mass & Isotope & mass & Isotope & mass \\
\hline${ }^{12} \mathrm{C}$ & $2.417 \mathrm{E}-01$ & ${ }^{46} \mathrm{Sc}$ & $1.775 \mathrm{E}-12$ & ${ }^{73} \mathrm{Ge}$ & $2.519 \mathrm{E}-09$ & $92 \mathrm{Mo}$ & $1.938 \mathrm{E}-08$ \\
\hline${ }^{13} \mathrm{C}$ & 7.670E-08 & ${ }^{44} \mathrm{Ti}$ & $6.014 \mathrm{E}-05$ & ${ }^{74} \mathrm{Ge}$ & $1.165 \mathrm{E}-07$ & $93 \mathrm{Mo}$ & $3.594 \mathrm{E}-10$ \\
\hline${ }^{14} \mathrm{C}$ & $3.219 \mathrm{E}-10$ & ${ }^{46} \mathrm{Ti}$ & $1.028 \mathrm{E}-06$ & ${ }^{76} \mathrm{Ge}$ & $1.761 \mathrm{E}-10$ & ${ }^{94} \mathrm{Mo}$ & $8.444 \mathrm{E}-10$ \\
\hline${ }^{14} \mathrm{~N}$ & $6.309 \mathrm{E}-04$ & ${ }^{47} \mathrm{Ti}$ & $3.714 \mathrm{E}-06$ & ${ }^{73} \mathrm{As}$ & $1.631 \mathrm{E}-08$ & ${ }^{95} \mathrm{Mo}$ & $2.131 \mathrm{E}-12$ \\
\hline${ }^{15} \mathrm{~N}$ & $5.305 \mathrm{E}-07$ & ${ }^{48} \mathrm{Ti}$ & $1.686 \mathrm{E}-04$ & ${ }^{75} \mathrm{As}$ & $1.821 \mathrm{E}-08$ & ${ }^{96} \mathrm{Mo}$ & $3.853 \mathrm{E}-12$ \\
\hline${ }^{16} \mathrm{O}$ & $2.043 \mathrm{E}+00$ & ${ }^{49} \mathrm{Ti}$ & $2.032 \mathrm{E}-09$ & ${ }^{74} \mathrm{Se}$ & $1.557 \mathrm{E}-07$ & ${ }^{97} \mathrm{Mo}$ & $9.491 \mathrm{E}-13$ \\
\hline${ }^{17} \mathrm{O}$ & $1.487 \mathrm{E}-06$ & ${ }^{50} \mathrm{Ti}$ & $2.123 \mathrm{E}-06$ & ${ }^{75} \mathrm{Se}$ & $6.738 \mathrm{E}-09$ & ${ }^{98} \mathrm{Mo}$ & $3.949 \mathrm{E}-13$ \\
\hline${ }^{18} \mathrm{O}$ & $5.541 \mathrm{E}-07$ & ${ }^{49} \mathrm{~V}$ & $1.819 \mathrm{E}-06$ & ${ }^{76} \mathrm{Se}$ & $5.390 \mathrm{E}-07$ & ${ }^{100} \mathrm{Mo}$ & $2.424 \mathrm{E}-14$ \\
\hline${ }^{19} \mathrm{~F}$ & $8.399 \mathrm{E}-08$ & ${ }^{50} \mathrm{~V}$ & $4.735 \mathrm{E}-11$ & ${ }^{77} \mathrm{Se}$ & 7.826E-09 & ${ }^{95} \mathrm{Tc}$ & $3.392 \mathrm{E}-10$ \\
\hline${ }^{20} \mathrm{Ne}$ & $1.646 \mathrm{E}-01$ & ${ }^{51} \mathrm{~V}$ & $8.739 \mathrm{E}-06$ & ${ }^{78} \mathrm{Se}$ & $2.277 \mathrm{E}-07$ & ${ }^{97} \mathrm{Tc}$ & $2.213 \mathrm{E}-10$ \\
\hline${ }^{21} \mathrm{Ne}$ & $8.490 \mathrm{E}-06$ & ${ }^{50} \mathrm{Cr}$ & $1.732 \mathrm{E}-06$ & ${ }^{79} \mathrm{Se}$ & $8.043 \mathrm{E}-10$ & ${ }^{98} \mathrm{Tc}$ & $4.076 \mathrm{E}-13$ \\
\hline${ }^{22} \mathrm{Ne}$ & $1.462 \mathrm{E}-06$ & ${ }^{52} \mathrm{Cr}$ & $1.782 \mathrm{E}-03$ & ${ }^{80} \mathrm{Se}$ & $1.292 \mathrm{E}-08$ & ${ }^{99} \mathrm{Tc}$ & $2.966 \mathrm{E}-13$ \\
\hline${ }^{22} \mathrm{Na}$ & 5.343E-06 & ${ }^{53} \mathrm{Cr}$ & $4.218 \mathrm{E}-07$ & ${ }^{82} \mathrm{Se}$ & $2.261 \mathrm{E}-11$ & ${ }^{96} \mathrm{Ru}$ & $9.833 \mathrm{E}-10$ \\
\hline${ }^{23} \mathrm{Na}$ & $2.018 \mathrm{E}-04$ & ${ }^{54} \mathrm{Cr}$ & $9.627 \mathrm{E}-06$ & ${ }^{79} \mathrm{Br}$ & $1.520 \mathrm{E}-08$ & ${ }^{98} \mathrm{Ru}$ & $4.396 \mathrm{E}-10$ \\
\hline${ }^{24} \mathrm{Mg}$ & $1.477 \mathrm{E}-01$ & ${ }^{53} \mathrm{Mn}$ & $4.536 \mathrm{E}-05$ & ${ }^{81} \mathrm{Br}$ & $1.551 \mathrm{E}-08$ & ${ }^{99} \mathrm{Ru}$ & $2.158 \mathrm{E}-10$ \\
\hline${ }^{25} \mathrm{Mg}$ & $1.102 \mathrm{E}-04$ & ${ }^{54} \mathrm{Mn}$ & $6.796 \mathrm{E}-09$ & ${ }^{78} \mathrm{Kr}$ & $3.737 \mathrm{E}-08$ & ${ }^{100} \mathrm{Ru}$ & $1.202 \mathrm{E}-09$ \\
\hline${ }^{26} \mathrm{Mg}$ & $2.944 \mathrm{E}-05$ & ${ }^{55} \mathrm{Mn}$ & $1.551 \mathrm{E}-06$ & ${ }^{80} \mathrm{Kr}$ & $9.522 \mathrm{E}-08$ & ${ }^{101} \mathrm{Ru}$ & $3.719 \mathrm{E}-13$ \\
\hline${ }^{26} \mathrm{Al}$ & $3.404 \mathrm{E}-06$ & ${ }^{54} \mathrm{Fe}$ & $1.958 \mathrm{E}-05$ & ${ }^{81} \mathrm{Kr}$ & $2.033 \mathrm{E}-09$ & ${ }^{102} \mathrm{Ru}$ & $2.289 \mathrm{E}-13$ \\
\hline${ }^{27} \mathrm{Al}$ & $1.036 \mathrm{E}-03$ & ${ }^{55} \mathrm{Fe}$ & $2.202 \mathrm{E}-05$ & ${ }^{82} \mathrm{Kr}$ & $1.194 \mathrm{E}-07$ & ${ }^{103} \mathrm{Ru}$ & $5.570 \mathrm{E}-13$ \\
\hline${ }^{28} \mathrm{Si}$ & $2.094 \mathrm{E}-01$ & ${ }^{56} \mathrm{Fe}$ & $1.968 \mathrm{E}-05$ & ${ }^{83} \mathrm{Kr}$ & $4.680 \mathrm{E}-09$ & ${ }^{104} \mathrm{Ru}$ & $9.821 \mathrm{E}-14$ \\
\hline${ }^{29} \mathrm{Si}$ & $5.847 \mathrm{E}-04$ & ${ }^{57} \mathrm{Fe}$ & 7.369E-07 & ${ }^{84} \mathrm{Kr}$ & $7.406 \mathrm{E}-08$ & ${ }^{106} \mathrm{Ru}$ & $5.831 \mathrm{E}-15$ \\
\hline${ }^{30} \mathrm{Si}$ & $9.516 \mathrm{E}-05$ & ${ }^{58} \mathrm{Fe}$ & $2.695 \mathrm{E}-05$ & ${ }^{85} \mathrm{Kr}$ & $4.080 \mathrm{E}-10$ & ${ }^{101} \mathrm{Rh}$ & $1.804 \mathrm{E}-10$ \\
\hline${ }^{32} \mathrm{Si}$ & $3.666 \mathrm{E}-13$ & ${ }^{59} \mathrm{Fe}$ & 8.949E-09 & ${ }^{86} \mathrm{Kr}$ & $6.256 \mathrm{E}-09$ & ${ }^{102} \mathrm{Rh}$ & $8.031 \mathrm{E}-14$ \\
\hline${ }^{31} \mathrm{P}$ & $6.653 \mathrm{E}-05$ & ${ }^{60} \mathrm{Fe}$ & $1.458 \mathrm{E}-08$ & ${ }^{83} \mathrm{Rb}$ & $5.462 \mathrm{E}-09$ & ${ }^{103} \mathrm{Rh}$ & $3.771 \mathrm{E}-11$ \\
\hline${ }^{32} \mathrm{~S}$ & $7.671 \mathrm{E}-02$ & ${ }^{56} \mathrm{Co}$ & $1.632 \mathrm{E}-07$ & ${ }^{84} \mathrm{Rb}$ & $4.166 \mathrm{E}-10$ & & \\
\hline${ }^{33} \mathrm{~S}$ & $1.964 \mathrm{E}-04$ & ${ }^{57} \mathrm{Co}$ & $1.380 \mathrm{E}-03$ & ${ }^{85} \mathrm{Rb}$ & $1.181 \mathrm{E}-08$ & & \\
\hline${ }^{34} \mathrm{~S}$ & $2.550 \mathrm{E}-05$ & ${ }^{58} \mathrm{Co}$ & 7.945E-09 & ${ }^{87} \mathrm{Rb}$ & $4.823 \mathrm{E}-08$ & & \\
\hline${ }^{35} \mathrm{~S}$ & $5.278 \mathrm{E}-10$ & ${ }^{59} \mathrm{Co}$ & $6.570 \mathrm{E}-07$ & ${ }^{84} \mathrm{Sr}$ & $4.984 \mathrm{E}-09$ & & \\
\hline${ }^{36} \mathrm{~S}$ & $5.323 \mathrm{E}-11$ & ${ }^{60} \mathrm{Co}$ & $8.377 \mathrm{E}-09$ & ${ }^{85} \mathrm{Sr}$ & $7.702 \mathrm{E}-10$ & & \\
\hline${ }^{35} \mathrm{Cl}$ & $1.503 \mathrm{E}-05$ & ${ }^{56} \mathrm{Ni}$ & $9.188 \mathrm{E}-02$ & ${ }^{86} \mathrm{Sr}$ & $1.225 \mathrm{E}-08$ & & \\
\hline${ }^{36} \mathrm{Cl}$ & $2.379 \mathrm{E}-08$ & ${ }^{58} \mathrm{Ni}$ & $7.591 \mathrm{E}-04$ & ${ }^{87} \mathrm{Sr}$ & $4.552 \mathrm{E}-09$ & & \\
\hline${ }^{37} \mathrm{Cl}$ & $2.221 \mathrm{E}-08$ & ${ }^{59} \mathrm{Ni}$ & $2.171 \mathrm{E}-04$ & ${ }^{88} \mathrm{Sr}$ & $6.533 \mathrm{E}-06$ & & \\
\hline${ }^{36} \mathrm{Ar}$ & $1.234 \mathrm{E}-02$ & ${ }^{60} \mathrm{Ni}$ & 2.070E-03 & ${ }^{89} \mathrm{Sr}$ & $4.130 \mathrm{E}-10$ & & \\
\hline${ }^{37} \mathrm{Ar}$ & $1.576 \mathrm{E}-05$ & ${ }^{61} \mathrm{Ni}$ & $3.764 \mathrm{E}-05$ & ${ }^{90} \mathrm{Sr}$ & $2.066 \mathrm{E}-12$ & & \\
\hline${ }^{38} \mathrm{Ar}$ & $7.734 \mathrm{E}-06$ & ${ }^{62} \mathrm{Ni}$ & $1.880 \mathrm{E}-04$ & ${ }^{88} \mathrm{Y}$ & $2.534 \mathrm{E}-10$ & & \\
\hline${ }^{39} \mathrm{Ar}$ & $2.101 \mathrm{E}-11$ & ${ }^{63} \mathrm{Ni}$ & $1.939 \mathrm{E}-07$ & ${ }^{89} \mathrm{Y}$ & $6.392 \mathrm{E}-07$ & & \\
\hline${ }^{40} \mathrm{Ar}$ & $3.820 \mathrm{E}-12$ & ${ }^{64} \mathrm{Ni}$ & $4.118 \mathrm{E}-06$ & ${ }^{91} \mathrm{Y}$ & $3.541 \mathrm{E}-12$ & & \\
\hline${ }^{42} \mathrm{Ar}$ & $5.836 \mathrm{E}-16$ & ${ }^{63} \mathrm{Cu}$ & $8.746 \mathrm{E}-06$ & ${ }^{88} \mathrm{Zr}$ & $8.341 \mathrm{E}-10$ & & \\
\hline${ }^{39} \mathrm{~K}$ & $4.466 \mathrm{E}-06$ & ${ }^{65} \mathrm{Cu}$ & $9.101 \mathrm{E}-07$ & ${ }^{90} \mathrm{Zr}$ & $2.578 \mathrm{E}-06$ & & \\
\hline${ }^{40} \mathrm{~K}$ & $5.160 \mathrm{E}-10$ & ${ }^{64} \mathrm{Zn}$ & $2.602 \mathrm{E}-04$ & ${ }^{91} \mathrm{Zr}$ & $2.876 \mathrm{E}-09$ & & \\
\hline${ }^{41} \mathrm{~K}$ & $1.293 \mathrm{E}-10$ & ${ }^{65} \mathrm{Zn}$ & $1.016 \mathrm{E}-06$ & ${ }^{92} \mathrm{Zr}$ & $2.143 \mathrm{E}-10$ & & \\
\hline${ }^{40} \mathrm{Ca}$ & $1.075 \mathrm{E}-02$ & ${ }^{66} \mathrm{Zn}$ & $4.431 \mathrm{E}-05$ & ${ }^{93} \mathrm{Zr}$ & $2.681 \mathrm{E}-13$ & & \\
\hline${ }^{41} \mathrm{Ca}$ & $1.993 \mathrm{E}-06$ & ${ }^{67} \mathrm{Zn}$ & $3.278 \mathrm{E}-07$ & ${ }^{94} \mathrm{Zr}$ & $1.224 \mathrm{E}-13$ & & \\
\hline${ }^{42} \mathrm{Ca}$ & $1.826 \mathrm{E}-07$ & ${ }^{68} \mathrm{Zn}$ & $2.972 \mathrm{E}-06$ & ${ }^{95} \mathrm{Zr}$ & $3.079 \mathrm{E}-13$ & & \\
\hline${ }^{43} \mathrm{Ca}$ & $5.851 \mathrm{E}-08$ & ${ }^{70} \mathrm{Zn}$ & $1.747 \mathrm{E}-09$ & ${ }^{96} \mathrm{Zr}$ & $5.192 \mathrm{E}-14$ & & \\
\hline${ }^{44} \mathrm{Ca}$ & $1.883 \mathrm{E}-10$ & ${ }^{69} \mathrm{Ga}$ & $1.988 \mathrm{E}-07$ & ${ }^{91} \mathrm{Nb}$ & $1.415 \mathrm{E}-08$ & & \\
\hline${ }^{45} \mathrm{Ca}$ & $3.175 \mathrm{E}-13$ & ${ }^{71} \mathrm{Ga}$ & $2.199 \mathrm{E}-08$ & ${ }^{92} \mathrm{Nb}$ & $6.286 \mathrm{E}-11$ & & \\
\hline${ }^{46} \mathrm{Ca}$ & $4.255 \mathrm{E}-11$ & ${ }^{68} \mathrm{Ge}$ & $4.524 \mathrm{E}-06$ & ${ }^{93} \mathrm{Nb}$ & $7.268 \mathrm{E}-12$ & & \\
\hline${ }^{48} \mathrm{Ca}$ & $2.025 \mathrm{E}-11$ & ${ }^{70} \mathrm{Ge}$ & $4.055 \mathrm{E}-06$ & ${ }^{94} \mathrm{Nb}$ & $2.663 \mathrm{E}-13$ & & \\
\hline${ }^{45} \mathrm{Sc}$ & $7.514 \mathrm{E}-08$ & ${ }^{72} \mathrm{Ge}$ & $1.481 \mathrm{E}-06$ & ${ }^{95} \mathrm{Nb}$ & $1.064 \mathrm{E}-12$ & & \\
\hline
\end{tabular}


TABLE 7

YIELDS $\left(\right.$ IN $M_{\odot}$ ) FOR THE MODEL 2520-4

\begin{tabular}{|c|c|c|c|c|c|c|c|}
\hline Isotope & mass & Isotope & mass & Isotope & mass & Isotope & mass \\
\hline${ }^{12} \mathrm{C}$ & $2.417 \mathrm{E}-01$ & ${ }^{46} \mathrm{Sc}$ & $2.184 \mathrm{E}-12$ & ${ }^{73} \mathrm{Ge}$ & 3.149E-09 & $92 \mathrm{Mo}$ & $2.423 \mathrm{E}-08$ \\
\hline${ }^{13} \mathrm{C}$ & 7.670E-08 & ${ }^{44} \mathrm{Ti}$ & $7.515 \mathrm{E}-05$ & ${ }^{74} \mathrm{Ge}$ & $1.456 \mathrm{E}-07$ & $93 \mathrm{Mo}$ & $4.492 \mathrm{E}-10$ \\
\hline${ }^{14} \mathrm{C}$ & $3.219 \mathrm{E}-10$ & ${ }^{46} \mathrm{Ti}$ & $1.274 \mathrm{E}-06$ & ${ }^{76} \mathrm{Ge}$ & $2.201 \mathrm{E}-10$ & ${ }^{94} \mathrm{Mo}$ & $1.056 \mathrm{E}-09$ \\
\hline${ }^{14} \mathrm{~N}$ & $6.309 \mathrm{E}-04$ & ${ }^{47} \mathrm{Ti}$ & $4.642 \mathrm{E}-06$ & ${ }^{73} \mathrm{As}$ & $2.039 \mathrm{E}-08$ & ${ }^{95} \mathrm{Mo}$ & $2.664 \mathrm{E}-12$ \\
\hline${ }^{15} \mathrm{~N}$ & $5.306 \mathrm{E}-07$ & ${ }^{48} \mathrm{Ti}$ & $2.107 \mathrm{E}-04$ & ${ }^{75} \mathrm{As}$ & $2.277 \mathrm{E}-08$ & ${ }^{96} \mathrm{Mo}$ & $4.817 \mathrm{E}-12$ \\
\hline${ }^{16} \mathrm{O}$ & $2.046 \mathrm{E}+00$ & ${ }^{49} \mathrm{Ti}$ & $2.540 \mathrm{E}-09$ & ${ }^{74} \mathrm{Se}$ & $1.946 \mathrm{E}-07$ & ${ }^{97} \mathrm{Mo}$ & $1.186 \mathrm{E}-12$ \\
\hline${ }^{17} \mathrm{O}$ & $1.487 \mathrm{E}-06$ & ${ }^{50} \mathrm{Ti}$ & $2.654 \mathrm{E}-06$ & ${ }^{75} \mathrm{Se}$ & $8.422 \mathrm{E}-09$ & ${ }^{98} \mathrm{Mo}$ & $4.936 \mathrm{E}-13$ \\
\hline${ }^{18} \mathrm{O}$ & $5.541 \mathrm{E}-07$ & ${ }^{49} \mathrm{~V}$ & $2.272 \mathrm{E}-06$ & ${ }^{76} \mathrm{Se}$ & $6.737 \mathrm{E}-07$ & ${ }^{100} \mathrm{Mo}$ & $3.030 \mathrm{E}-14$ \\
\hline${ }^{19} \mathrm{~F}$ & $8.399 \mathrm{E}-08$ & ${ }^{50} \mathrm{~V}$ & $5.902 \mathrm{E}-11$ & ${ }^{77} \mathrm{Se}$ & $9.783 \mathrm{E}-09$ & ${ }^{95} \mathrm{Tc}$ & $4.240 \mathrm{E}-10$ \\
\hline${ }^{20} \mathrm{Ne}$ & $1.646 \mathrm{E}-01$ & ${ }^{51} \mathrm{~V}$ & $1.092 \mathrm{E}-05$ & ${ }^{78} \mathrm{Se}$ & $2.846 \mathrm{E}-07$ & ${ }^{97} \mathrm{Tc}$ & $2.767 \mathrm{E}-10$ \\
\hline${ }^{21} \mathrm{Ne}$ & $8.490 \mathrm{E}-06$ & ${ }^{50} \mathrm{Cr}$ & $2.135 \mathrm{E}-06$ & ${ }^{79} \mathrm{Se}$ & $1.005 \mathrm{E}-09$ & ${ }^{98} \mathrm{Tc}$ & $5.095 \mathrm{E}-13$ \\
\hline${ }^{22} \mathrm{Ne}$ & $1.462 \mathrm{E}-06$ & ${ }^{52} \mathrm{Cr}$ & $2.227 \mathrm{E}-03$ & ${ }^{80} \mathrm{Se}$ & $1.615 \mathrm{E}-08$ & ${ }^{99} \mathrm{Tc}$ & $3.707 \mathrm{E}-13$ \\
\hline${ }^{22} \mathrm{Na}$ & 5.343E-06 & ${ }^{53} \mathrm{Cr}$ & $5.273 \mathrm{E}-07$ & ${ }^{82} \mathrm{Se}$ & $2.826 \mathrm{E}-11$ & ${ }^{96} \mathrm{Ru}$ & $1.229 \mathrm{E}-09$ \\
\hline${ }^{23} \mathrm{Na}$ & $2.018 \mathrm{E}-04$ & ${ }^{54} \mathrm{Cr}$ & $1.203 \mathrm{E}-05$ & ${ }^{79} \mathrm{Br}$ & $1.901 \mathrm{E}-08$ & ${ }^{98} \mathrm{Ru}$ & $5.495 \mathrm{E}-10$ \\
\hline${ }^{24} \mathrm{Mg}$ & $1.477 \mathrm{E}-01$ & ${ }^{53} \mathrm{Mn}$ & $5.670 \mathrm{E}-05$ & ${ }^{81} \mathrm{Br}$ & $1.939 \mathrm{E}-08$ & ${ }^{99} \mathrm{Ru}$ & $2.697 \mathrm{E}-10$ \\
\hline${ }^{25} \mathrm{Mg}$ & $1.102 \mathrm{E}-04$ & ${ }^{54} \mathrm{Mn}$ & $8.493 \mathrm{E}-09$ & ${ }^{78} \mathrm{Kr}$ & $4.669 \mathrm{E}-08$ & ${ }^{100} \mathrm{Ru}$ & $1.503 \mathrm{E}-09$ \\
\hline${ }^{26} \mathrm{Mg}$ & $2.944 \mathrm{E}-05$ & ${ }^{55} \mathrm{Mn}$ & $1.939 \mathrm{E}-06$ & ${ }^{80} \mathrm{Kr}$ & $1.190 \mathrm{E}-07$ & ${ }^{101} \mathrm{Ru}$ & $4.649 \mathrm{E}-13$ \\
\hline${ }^{26} \mathrm{Al}$ & $3.417 \mathrm{E}-06$ & ${ }^{54} \mathrm{Fe}$ & $2.434 \mathrm{E}-05$ & ${ }^{81} \mathrm{Kr}$ & $2.541 \mathrm{E}-09$ & ${ }^{102} \mathrm{Ru}$ & $2.861 \mathrm{E}-13$ \\
\hline${ }^{27} \mathrm{Al}$ & $1.036 \mathrm{E}-03$ & ${ }^{55} \mathrm{Fe}$ & $2.752 \mathrm{E}-05$ & ${ }^{82} \mathrm{Kr}$ & $1.493 \mathrm{E}-07$ & ${ }^{103} \mathrm{Ru}$ & $6.963 \mathrm{E}-13$ \\
\hline${ }^{28} \mathrm{Si}$ & $2.261 \mathrm{E}-01$ & ${ }^{56} \mathrm{Fe}$ & $2.459 \mathrm{E}-05$ & ${ }^{83} \mathrm{Kr}$ & $5.850 \mathrm{E}-09$ & ${ }^{104} \mathrm{Ru}$ & $1.228 \mathrm{E}-13$ \\
\hline${ }^{29} \mathrm{Si}$ & $5.859 \mathrm{E}-04$ & ${ }^{57} \mathrm{Fe}$ & $9.211 \mathrm{E}-07$ & ${ }^{84} \mathrm{Kr}$ & $9.257 \mathrm{E}-08$ & ${ }^{106} \mathrm{Ru}$ & $7.289 \mathrm{E}-15$ \\
\hline${ }^{30} \mathrm{Si}$ & $9.565 \mathrm{E}-05$ & ${ }^{58} \mathrm{Fe}$ & $3.369 \mathrm{E}-05$ & ${ }^{85} \mathrm{Kr}$ & $5.100 \mathrm{E}-10$ & ${ }^{101} \mathrm{Rh}$ & $2.255 \mathrm{E}-10$ \\
\hline${ }^{32} \mathrm{Si}$ & $3.753 \mathrm{E}-13$ & ${ }^{59} \mathrm{Fe}$ & $1.119 \mathrm{E}-08$ & ${ }^{86} \mathrm{Kr}$ & $7.820 \mathrm{E}-09$ & ${ }^{102} \mathrm{Rh}$ & $1.004 \mathrm{E}-13$ \\
\hline${ }^{31} \mathrm{P}$ & $6.763 \mathrm{E}-05$ & ${ }^{60} \mathrm{Fe}$ & $1.823 \mathrm{E}-08$ & ${ }^{83} \mathrm{Rb}$ & $6.827 \mathrm{E}-09$ & ${ }^{103} \mathrm{Rh}$ & $4.714 \mathrm{E}-11$ \\
\hline${ }^{32} \mathrm{~S}$ & $8.853 \mathrm{E}-02$ & ${ }^{56} \mathrm{Co}$ & $2.038 \mathrm{E}-07$ & ${ }^{84} \mathrm{Rb}$ & $5.207 \mathrm{E}-10$ & & \\
\hline${ }^{33} \mathrm{~S}$ & $1.983 \mathrm{E}-04$ & ${ }^{57} \mathrm{Co}$ & $1.725 \mathrm{E}-03$ & ${ }^{85} \mathrm{Rb}$ & $1.477 \mathrm{E}-08$ & & \\
\hline${ }^{34} \mathrm{~S}$ & $2.648 \mathrm{E}-05$ & ${ }^{58} \mathrm{Co}$ & $9.927 \mathrm{E}-09$ & ${ }^{87} \mathrm{Rb}$ & $6.028 \mathrm{E}-08$ & & \\
\hline${ }^{35} \mathrm{~S}$ & $5.279 \mathrm{E}-10$ & ${ }^{59} \mathrm{Co}$ & $8.212 \mathrm{E}-07$ & ${ }^{84} \mathrm{Sr}$ & $6.221 \mathrm{E}-09$ & & \\
\hline${ }^{36} \mathrm{~S}$ & $5.534 \mathrm{E}-11$ & ${ }^{60} \mathrm{Co}$ & $1.047 \mathrm{E}-08$ & ${ }^{85} \mathrm{Sr}$ & $9.622 \mathrm{E}-10$ & & \\
\hline${ }^{35} \mathrm{Cl}$ & $1.610 \mathrm{E}-05$ & ${ }^{56} \mathrm{Ni}$ & $1.149 \mathrm{E}-01$ & ${ }^{86} \mathrm{Sr}$ & $1.531 \mathrm{E}-08$ & & \\
\hline${ }^{36} \mathrm{Cl}$ & $2.384 \mathrm{E}-08$ & ${ }^{58} \mathrm{Ni}$ & $9.488 \mathrm{E}-04$ & ${ }^{87} \mathrm{Sr}$ & $5.690 \mathrm{E}-09$ & & \\
\hline${ }^{37} \mathrm{Cl}$ & $2.223 \mathrm{E}-08$ & ${ }^{59} \mathrm{Ni}$ & $2.714 \mathrm{E}-04$ & ${ }^{88} \mathrm{Sr}$ & $8.166 \mathrm{E}-06$ & & \\
\hline${ }^{36} \mathrm{Ar}$ & $1.486 \mathrm{E}-02$ & ${ }^{60} \mathrm{Ni}$ & $2.587 \mathrm{E}-03$ & ${ }^{89} \mathrm{Sr}$ & $5.163 \mathrm{E}-10$ & & \\
\hline${ }^{37} \mathrm{Ar}$ & $1.626 \mathrm{E}-05$ & ${ }^{61} \mathrm{Ni}$ & $4.706 \mathrm{E}-05$ & ${ }^{90} \mathrm{Sr}$ & $2.583 \mathrm{E}-12$ & & \\
\hline${ }^{38} \mathrm{Ar}$ & $8.030 \mathrm{E}-06$ & ${ }^{62} \mathrm{Ni}$ & $2.350 \mathrm{E}-04$ & ${ }^{88} \mathrm{Y}$ & $3.168 \mathrm{E}-10$ & & \\
\hline${ }^{39} \mathrm{Ar}$ & $2.157 \mathrm{E}-11$ & ${ }^{63} \mathrm{Ni}$ & $2.424 \mathrm{E}-07$ & ${ }^{89} \mathrm{Y}$ & $7.990 \mathrm{E}-07$ & & \\
\hline${ }^{40} \mathrm{Ar}$ & $4.532 \mathrm{E}-12$ & ${ }^{64} \mathrm{Ni}$ & $5.147 \mathrm{E}-06$ & ${ }^{91} \mathrm{Y}$ & $4.427 \mathrm{E}-12$ & & \\
\hline${ }^{42} \mathrm{Ar}$ & $6.299 \mathrm{E}-16$ & ${ }^{63} \mathrm{Cu}$ & $1.093 \mathrm{E}-05$ & ${ }^{88} \mathrm{Zr}$ & $1.042 \mathrm{E}-09$ & & \\
\hline${ }^{39} \mathrm{~K}$ & $4.955 \mathrm{E}-06$ & ${ }^{65} \mathrm{Cu}$ & $1.138 \mathrm{E}-06$ & ${ }^{90} \mathrm{Zr}$ & $3.222 \mathrm{E}-06$ & & \\
\hline${ }^{40} \mathrm{~K}$ & $5.257 \mathrm{E}-10$ & ${ }^{64} \mathrm{Zn}$ & $3.253 \mathrm{E}-04$ & ${ }^{91} \mathrm{Zr}$ & $3.594 \mathrm{E}-09$ & & \\
\hline${ }^{41} \mathrm{~K}$ & $1.372 \mathrm{E}-10$ & ${ }^{65} \mathrm{Zn}$ & $1.271 \mathrm{E}-06$ & ${ }^{92} \mathrm{Zr}$ & $2.679 \mathrm{E}-10$ & & \\
\hline${ }^{40} \mathrm{Ca}$ & $1.334 \mathrm{E}-02$ & ${ }^{66} \mathrm{Zn}$ & $5.539 \mathrm{E}-05$ & ${ }^{93} \mathrm{Zr}$ & $3.352 \mathrm{E}-13$ & & \\
\hline${ }^{41} \mathrm{Ca}$ & $2.163 \mathrm{E}-06$ & ${ }^{67} \mathrm{Zn}$ & $4.097 \mathrm{E}-07$ & ${ }^{94} \mathrm{Zr}$ & $1.527 \mathrm{E}-13$ & & \\
\hline${ }^{42} \mathrm{Ca}$ & $1.934 \mathrm{E}-07$ & ${ }^{68} \mathrm{Zn}$ & $3.715 \mathrm{E}-06$ & ${ }^{95} \mathrm{Zr}$ & $3.849 \mathrm{E}-13$ & & \\
\hline${ }^{43} \mathrm{Ca}$ & 7.309E-08 & ${ }^{70} \mathrm{Zn}$ & $2.183 \mathrm{E}-09$ & ${ }^{96} \mathrm{Zr}$ & $6.485 \mathrm{E}-14$ & & \\
\hline${ }^{44} \mathrm{Ca}$ & $2.157 \mathrm{E}-10$ & ${ }^{69} \mathrm{Ga}$ & $2.485 \mathrm{E}-07$ & ${ }^{91} \mathrm{Nb}$ & $1.768 \mathrm{E}-08$ & & \\
\hline${ }^{45} \mathrm{Ca}$ & $3.950 \mathrm{E}-13$ & ${ }^{71} \mathrm{Ga}$ & $2.748 \mathrm{E}-08$ & ${ }^{92} \mathrm{Nb}$ & $7.857 \mathrm{E}-11$ & & \\
\hline${ }^{46} \mathrm{Ca}$ & $5.316 \mathrm{E}-11$ & ${ }^{68} \mathrm{Ge}$ & $5.655 \mathrm{E}-06$ & ${ }^{93} \mathrm{Nb}$ & $9.085 \mathrm{E}-12$ & & \\
\hline${ }^{48} \mathrm{Ca}$ & $2.474 \mathrm{E}-11$ & ${ }^{70} \mathrm{Ge}$ & $5.068 \mathrm{E}-06$ & ${ }^{94} \mathrm{Nb}$ & $3.329 \mathrm{E}-13$ & & \\
\hline${ }^{45} \mathrm{Sc}$ & $9.122 \mathrm{E}-08$ & ${ }^{72} \mathrm{Ge}$ & $1.851 \mathrm{E}-06$ & ${ }^{95} \mathrm{Nb}$ & $1.329 \mathrm{E}-12$ & & \\
\hline
\end{tabular}



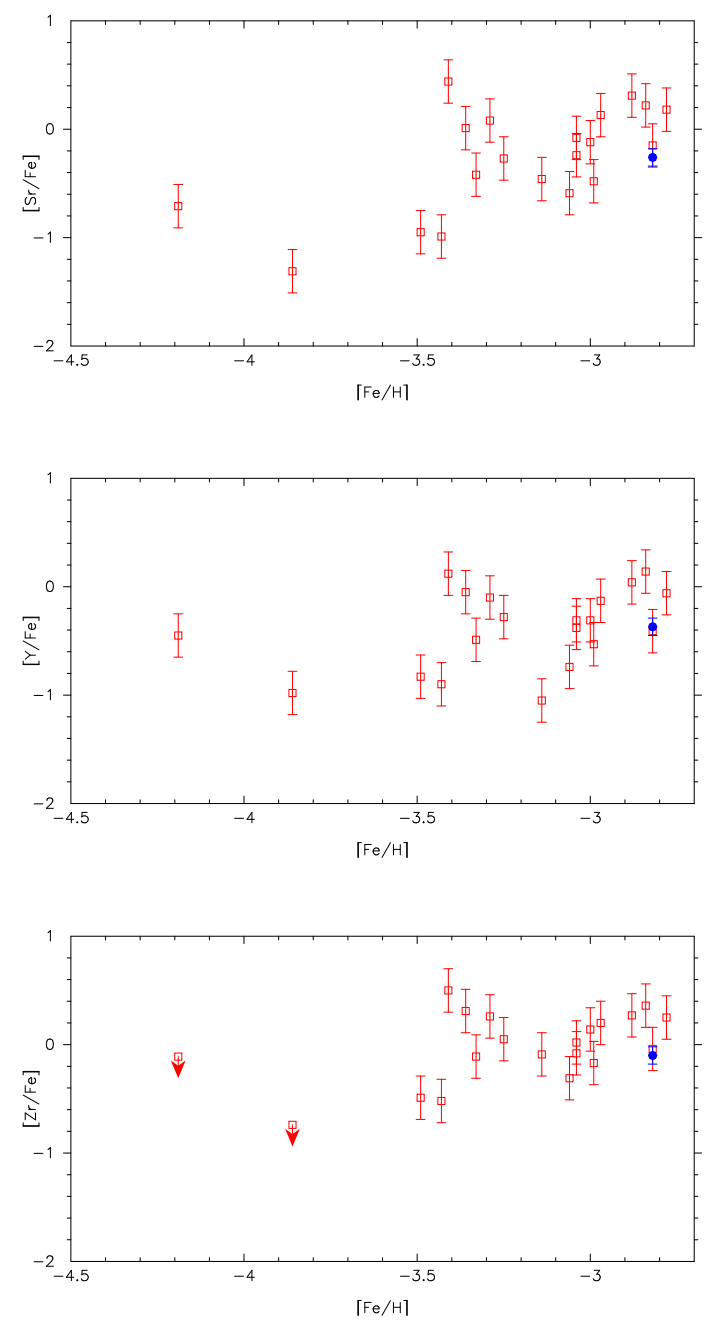

Fig. 1. $-[\mathrm{Sr} / \mathrm{Fe}]$ vs. $[\mathrm{Fe} / \mathrm{H}],[\mathrm{Y} / \mathrm{Fe}]$ vs. $[\mathrm{Fe} / \mathrm{H}]$, and $[\mathrm{Zr} / \mathrm{Fe}]$ vs. $[\mathrm{Fe} / \mathrm{H}]$ of "weak r-process stars". The solid circle point indicates HD122563 from Honda et al. (2006). Other data are taken from Francois et al. (2007). 

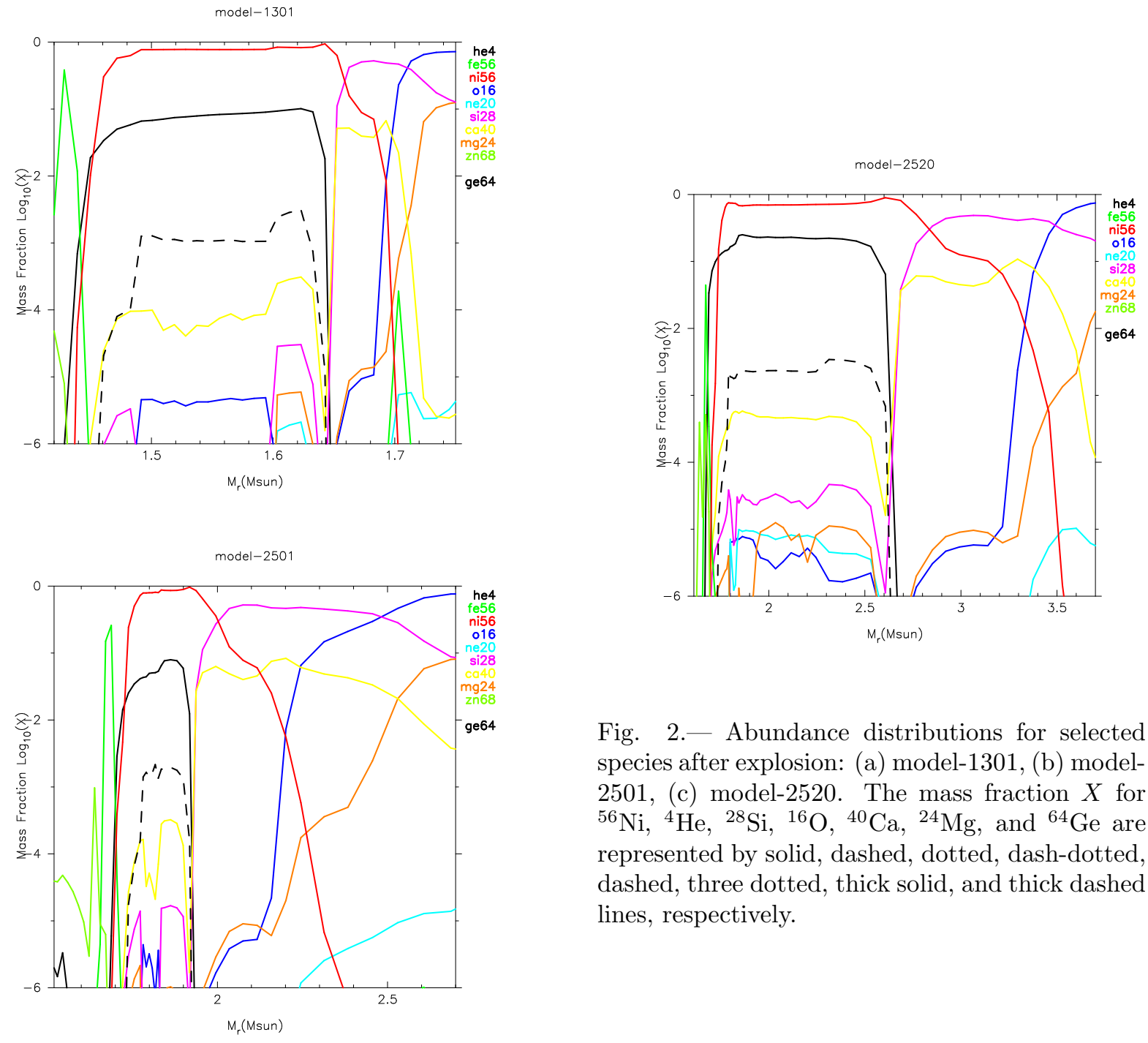

Fig. 2.- Abundance distributions for selected species after explosion: (a) model-1301, (b) model2501, (c) model-2520. The mass fraction $X$ for ${ }^{56} \mathrm{Ni},{ }^{4} \mathrm{He},{ }^{28} \mathrm{Si},{ }^{16} \mathrm{O},{ }^{40} \mathrm{Ca},{ }^{24} \mathrm{Mg}$, and ${ }^{64} \mathrm{Ge}$ are represented by solid, dashed, dotted, dash-dotted, dashed, three dotted, thick solid, and thick dashed lines, respectively. 

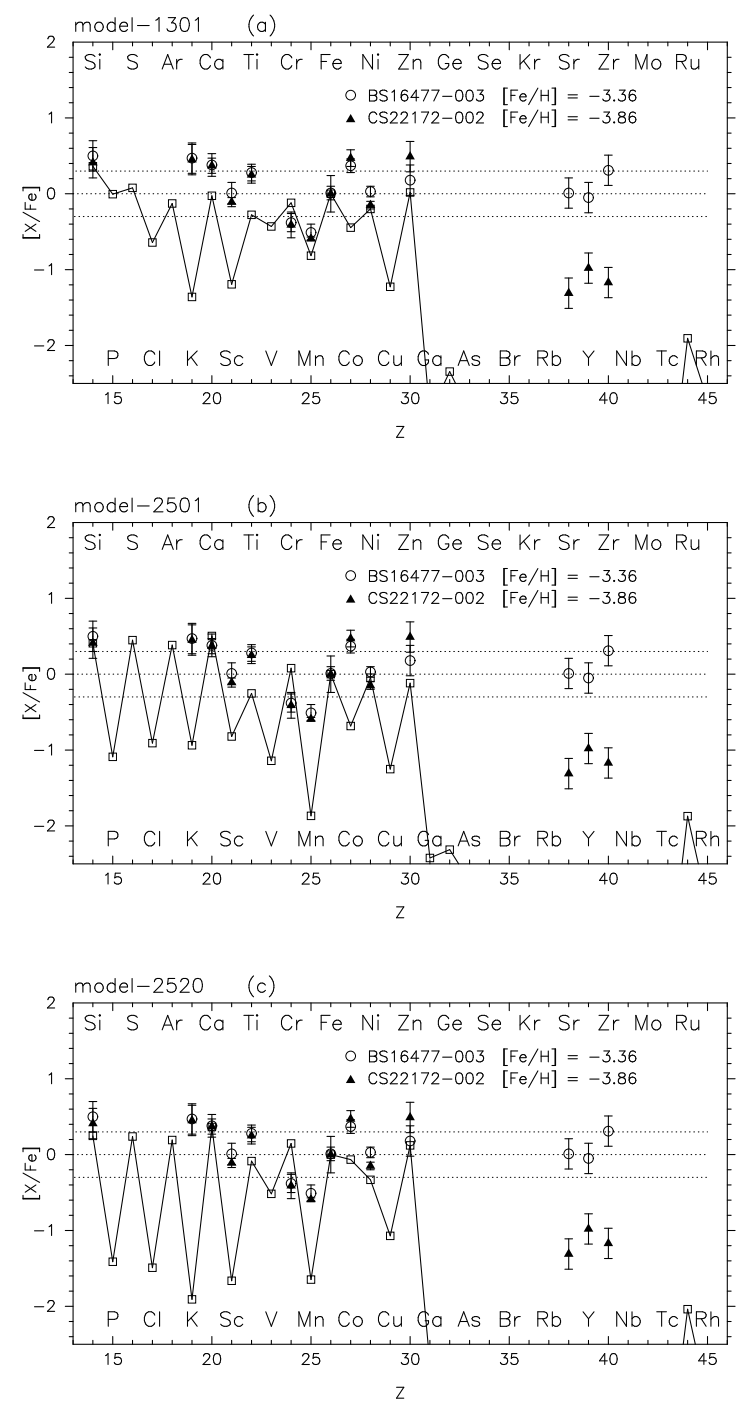

Fig. 3.- Comparisons between our models with conventional mass-cut and the abundance patterns of weak r-process stars. Panels (a), (b), and (c) are model-1301, model-2501 and model2520 , respectively. Mass-cuts are $M_{\text {cut }}=1.59 M_{\odot}$, $1.76 M_{\odot}$ and $2.31 M_{\odot}$ for model-1301, model-2501 and model-2520, respectively. BS16477-003 is the weak r-process star with the highest abundance of Sr, Y and Zr, and CS22172-002 is the weak rprocess star with the lowest abundance of these elements.

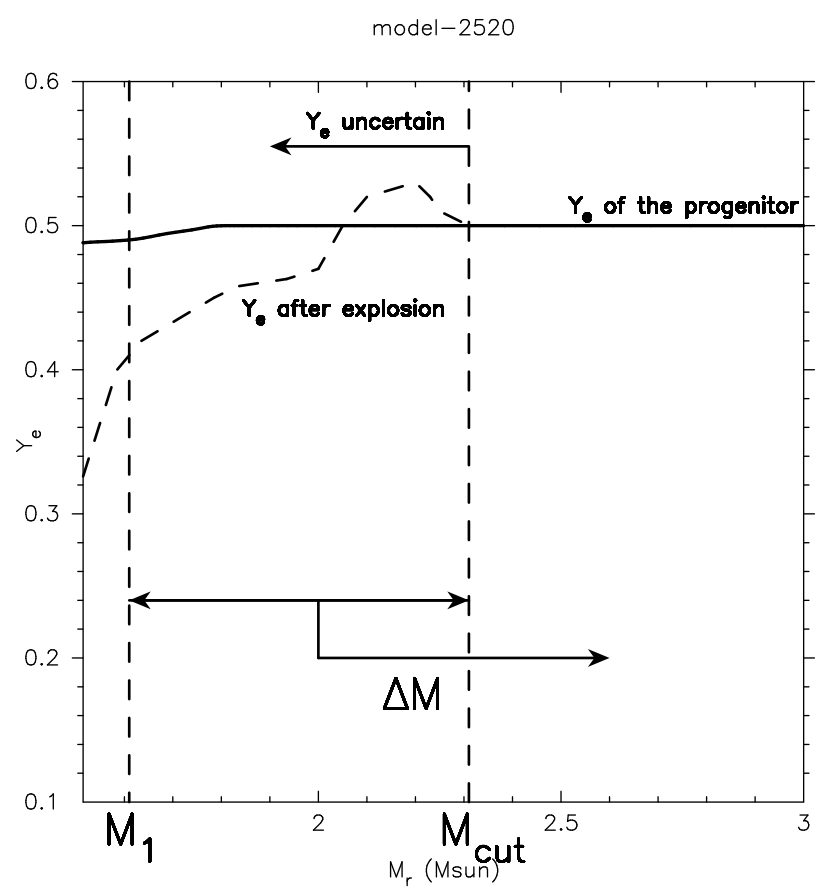

Fig. 4.- Illustration of $M_{1}, M_{\text {cut }}, \Delta M$, and $Y_{\mathrm{e}}$ distribution before and after explosion described in Section 4.1. 


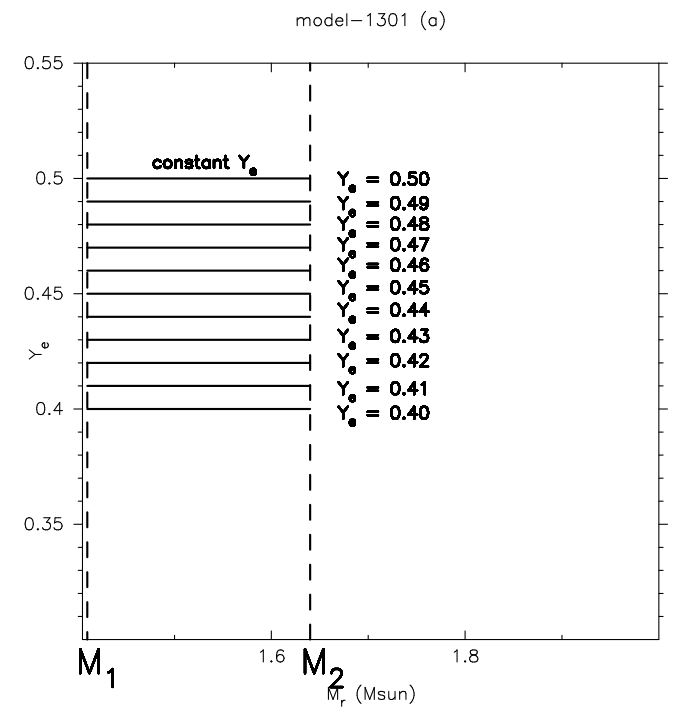

model-2501 (b)

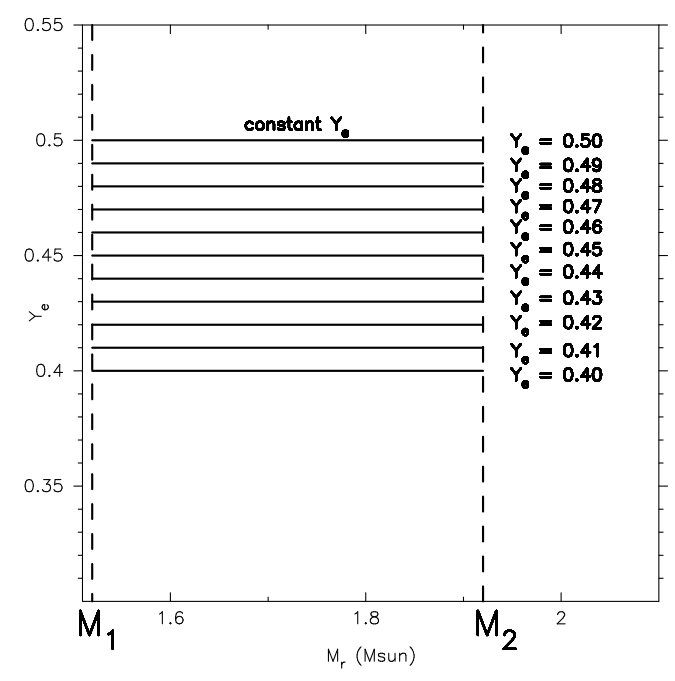

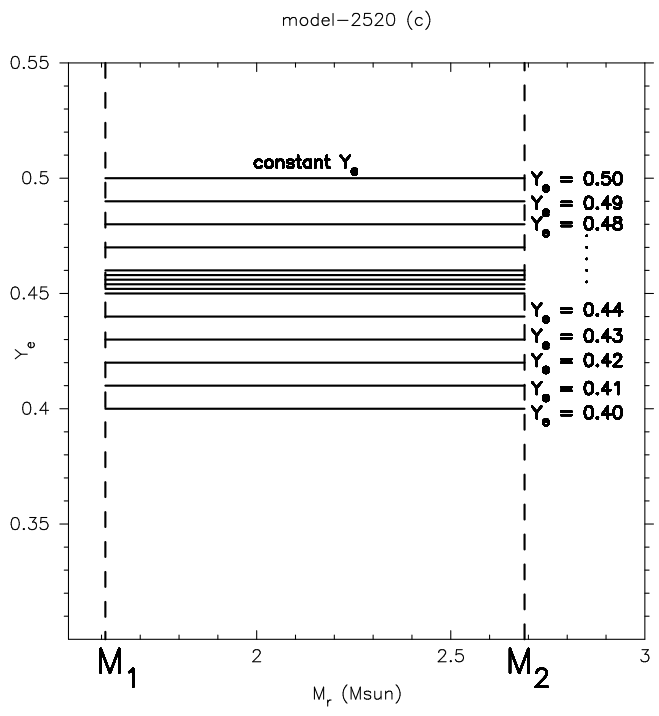

Fig. 5.- Illustrations of $M_{1}, M_{2}$, and $Y_{\mathrm{e}}$ in Section 4.2. Panels (a), (b) and (c) are model-1301, model-2501 and model-2520, respectively. $M_{1}$ and $M_{2}$ are the inner and outer boundaries of the calculated region, i.e., the complete Si-burning region, respectively. We carry out the nucleosynthesis calculation in the region $M_{1}<M<M_{2}$ with constant $Y_{\mathrm{e}}$ from 0.40 to 0.50 as shown in solid lines. 

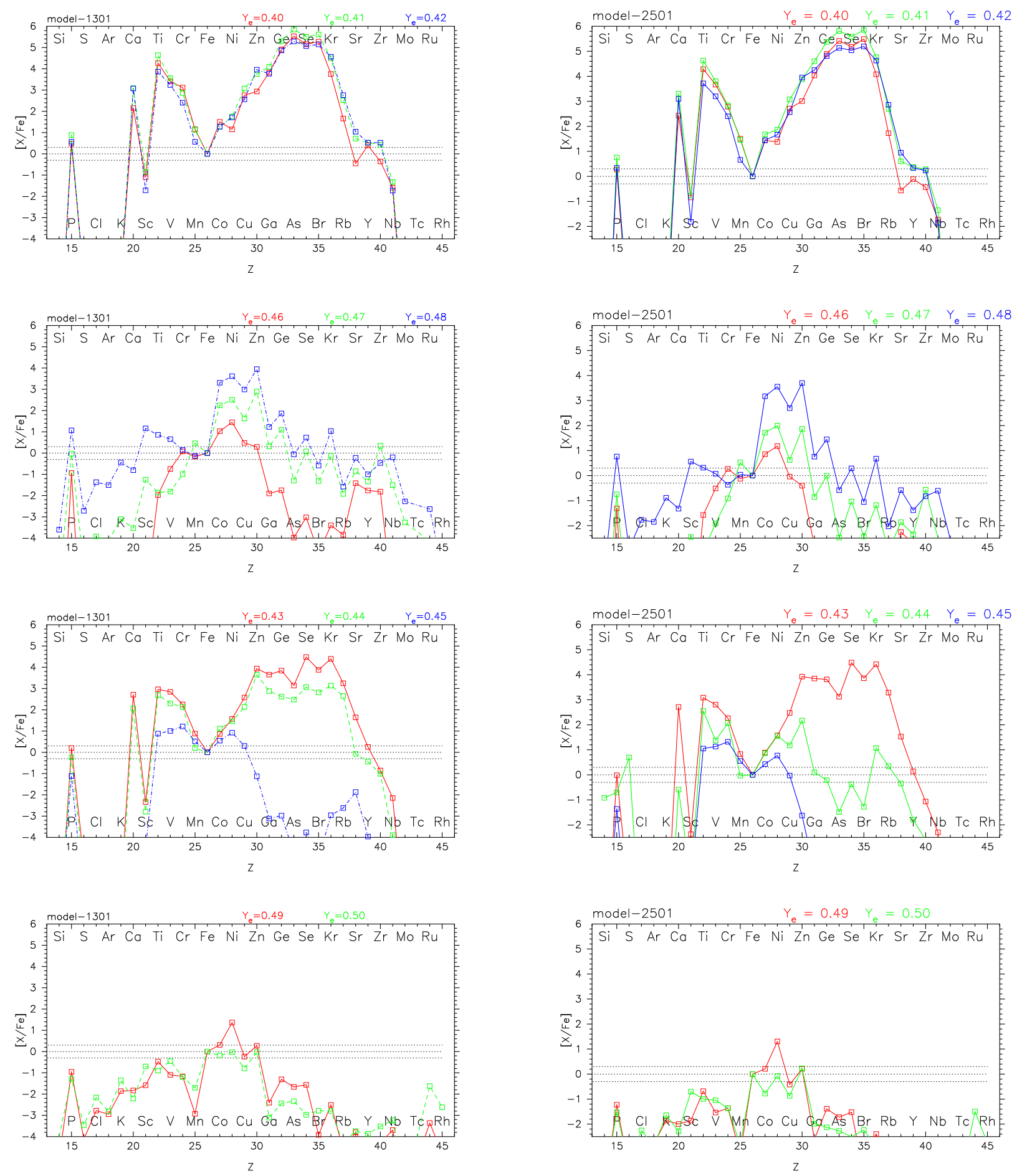

Fig. 6.- Abundance patterns in the Si-burning regions of model-1301 with each $Y_{e}$. The left panels: $Y_{e}=0.40,0.41,0.42$ and $Y_{e}=0.43,0.44,0.45$ (from the top). The right panels: $Y_{e}=0.46,0.47$, 0.48 and $Y_{e}=0.49,0.50$ (from the top).

Fig. 7.- Abundance patterns in the Si-burning regions of model-2501 with each $Y_{e}$. The left panels: $Y_{e}=0.40,0.41,0.42$ and $Y_{e}=0.43,0.44,0.45$ (from the top). The right panels: $Y_{e}=0.46,0.47$, 0.48 and $Y_{e}=0.49,0.50$ (from the top). 

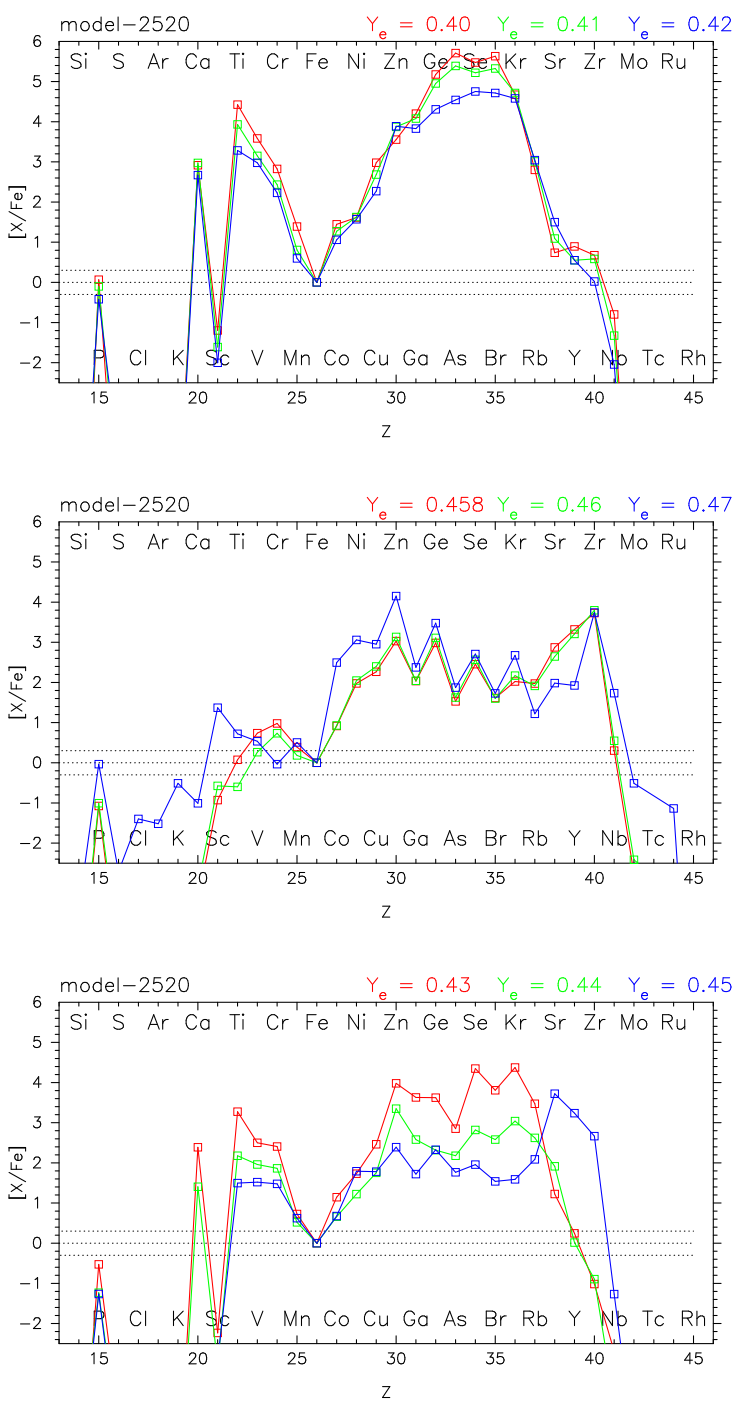
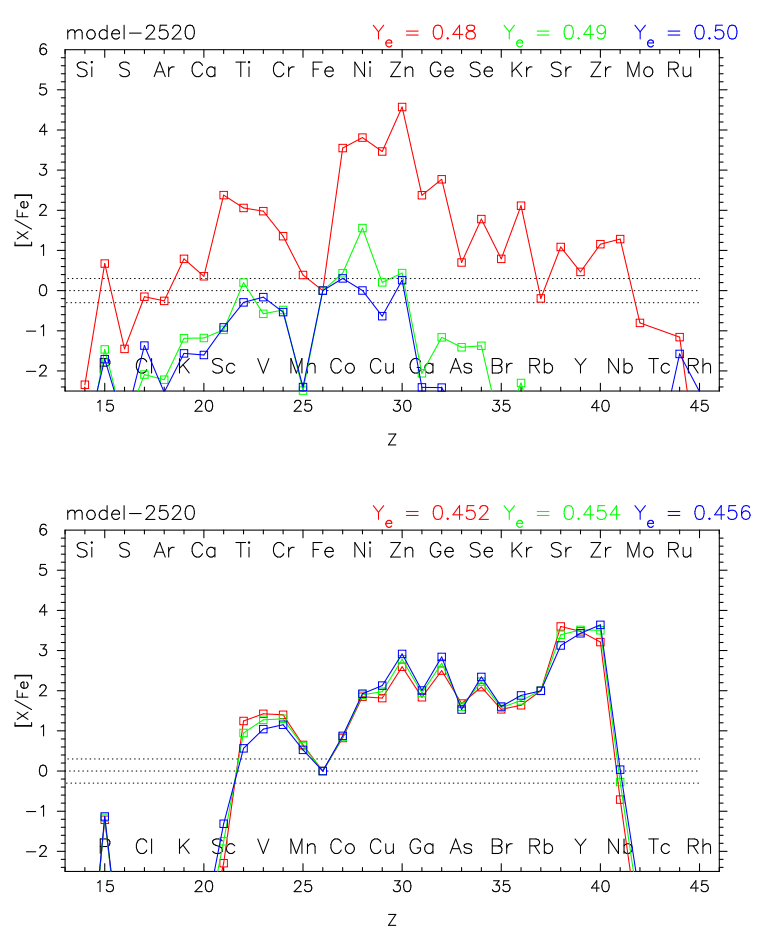

Fig. 8.- Abundance patterns in the Si-burning regions of model-2520 with each $Y_{e}$. The left panels: $Y_{e}=0.40,0.41,0.42, Y_{e}=0.43,0.44,0.45$ and $Y_{e}=0.452,0.454,0.456$ (from the top). The right panels: $Y_{e}=0.458,0.46,0.47$ and $Y_{e}=0.48$, $0.49,0.50$ (from the top). 

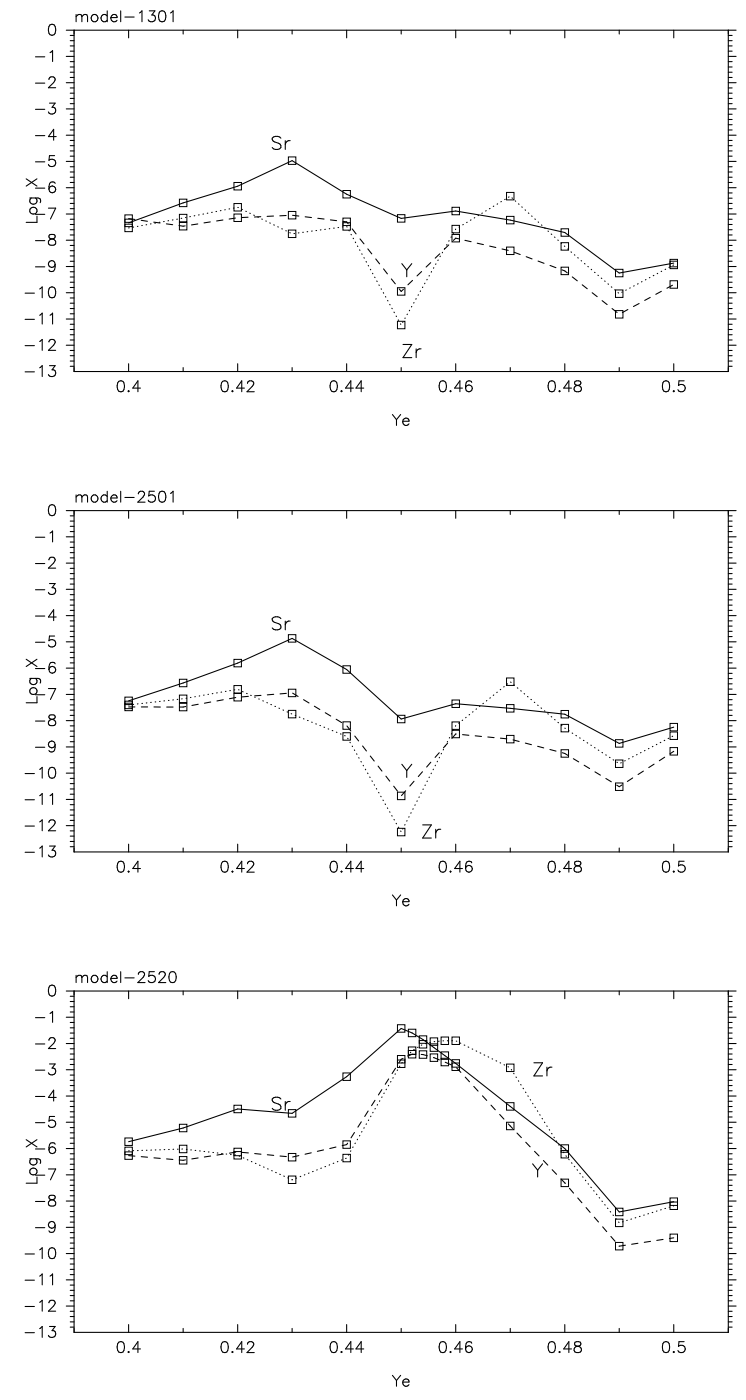

Fig. 9. - The mass fraction in the Si-burning regions of Sr, Y and Zr. The lines for Sr, Y, and Zr are represented by the solid line, dashed line, and dotted lines, respectively.
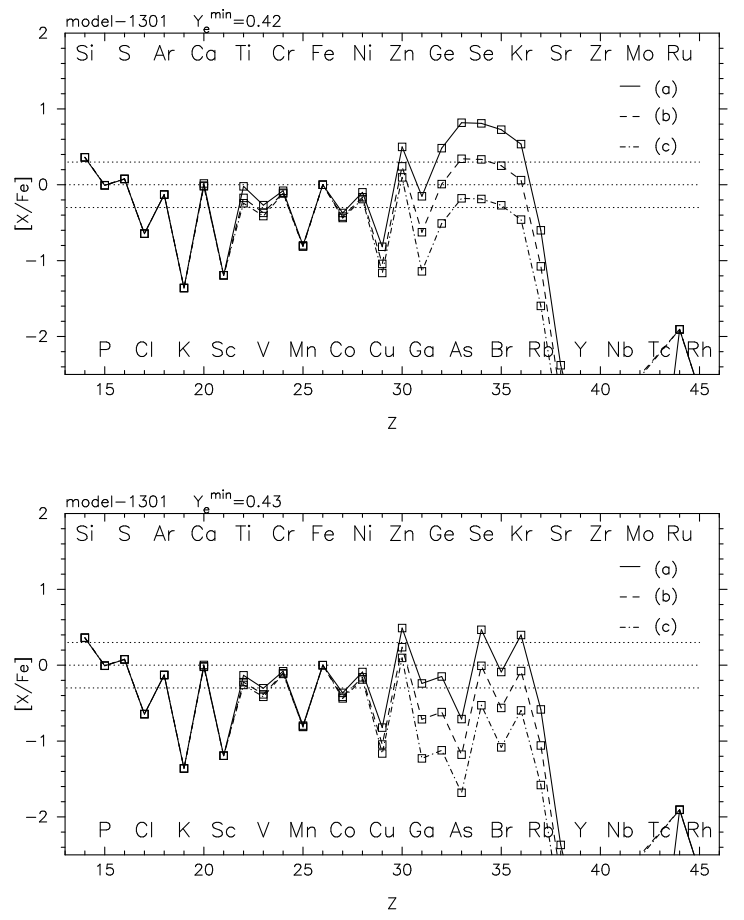

Fig. 10.- Abundance patterns of the whole ejecta for model-1301 with each $Y_{\mathrm{e}}$ distribution and $\Delta M$. Here, the abundance below $M_{\text {cut }}$ is averaged for $Y_{\mathrm{e}}$ $=Y_{\mathrm{e}}^{\min } \sim 0.50$. The parameters and some related numbers for models (a) are shown in Table 2. For the models (b) and (c), $\Delta M$ of model (a) is divided by 3 and 10 , respectively. 

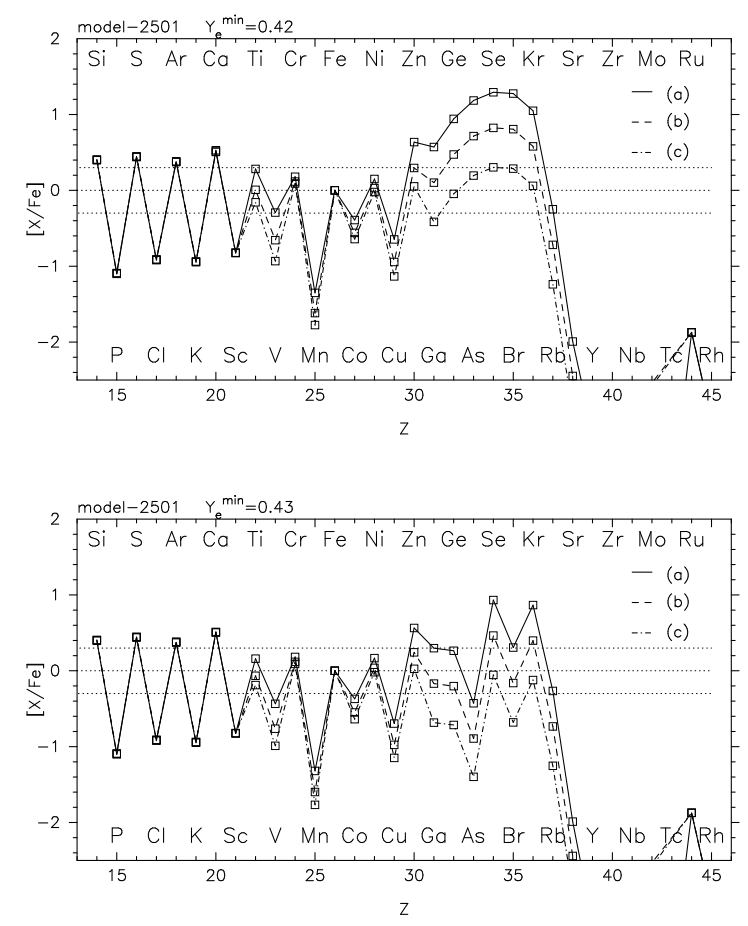

Fig. 11.- Same as Figure 10, but for model-2501. 

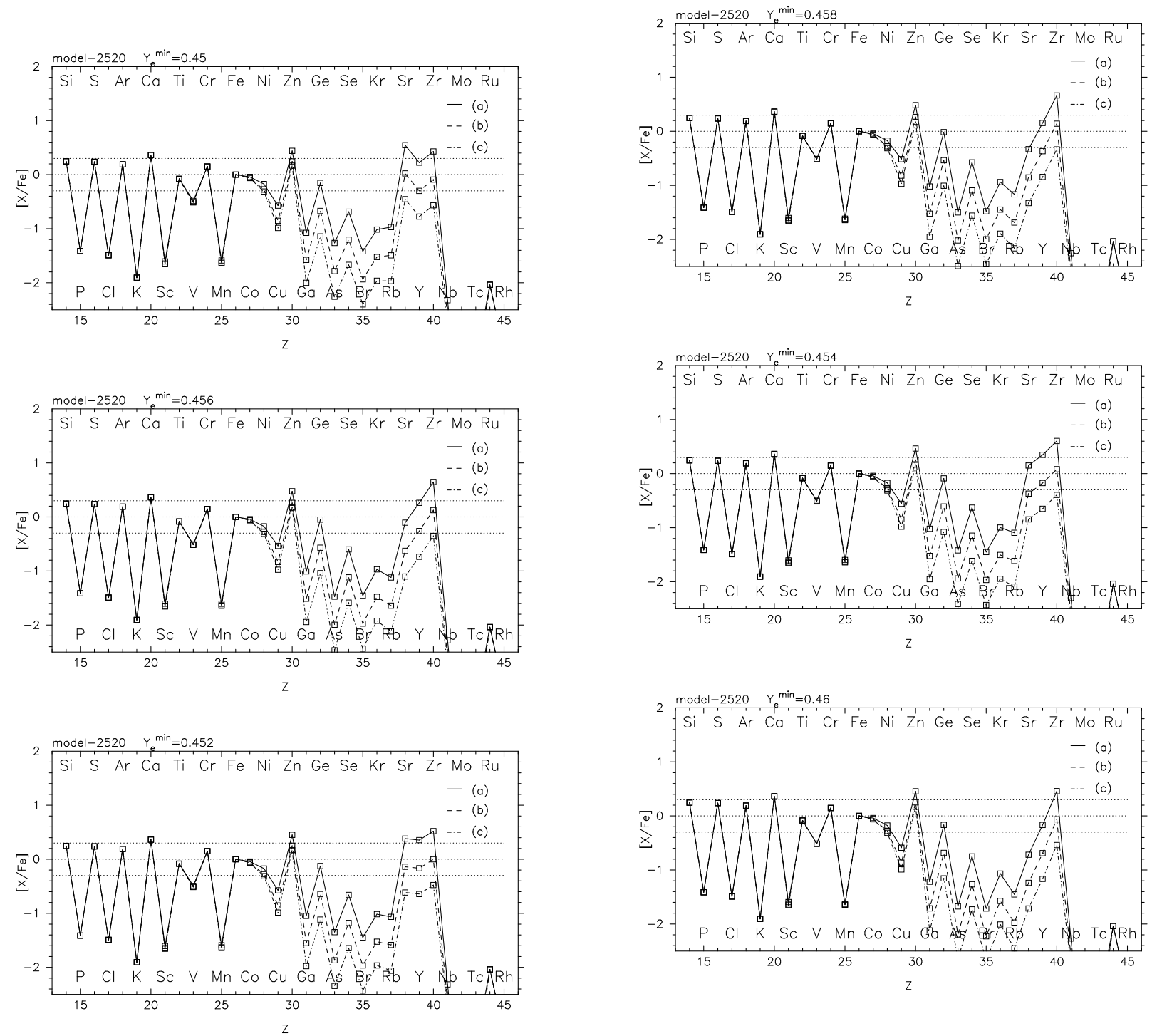

Fig. 12. - Same as Figure 10, but for model-2520 with different values of $Y_{\mathrm{e}}^{\mathrm{min}}$. 

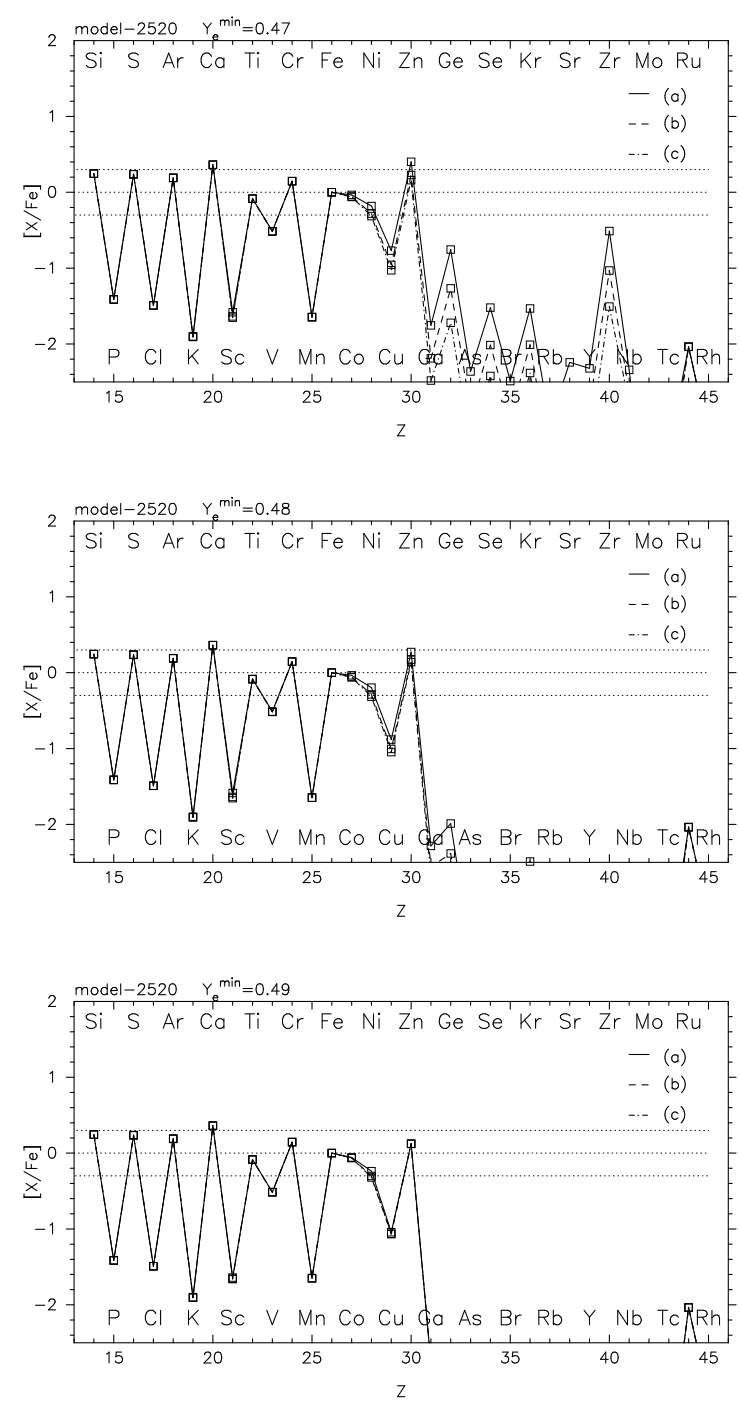

Fig. 13.- Same as Figure 10, but for model-2520 with different values of $Y_{\mathrm{e}}^{\mathrm{min}}$.
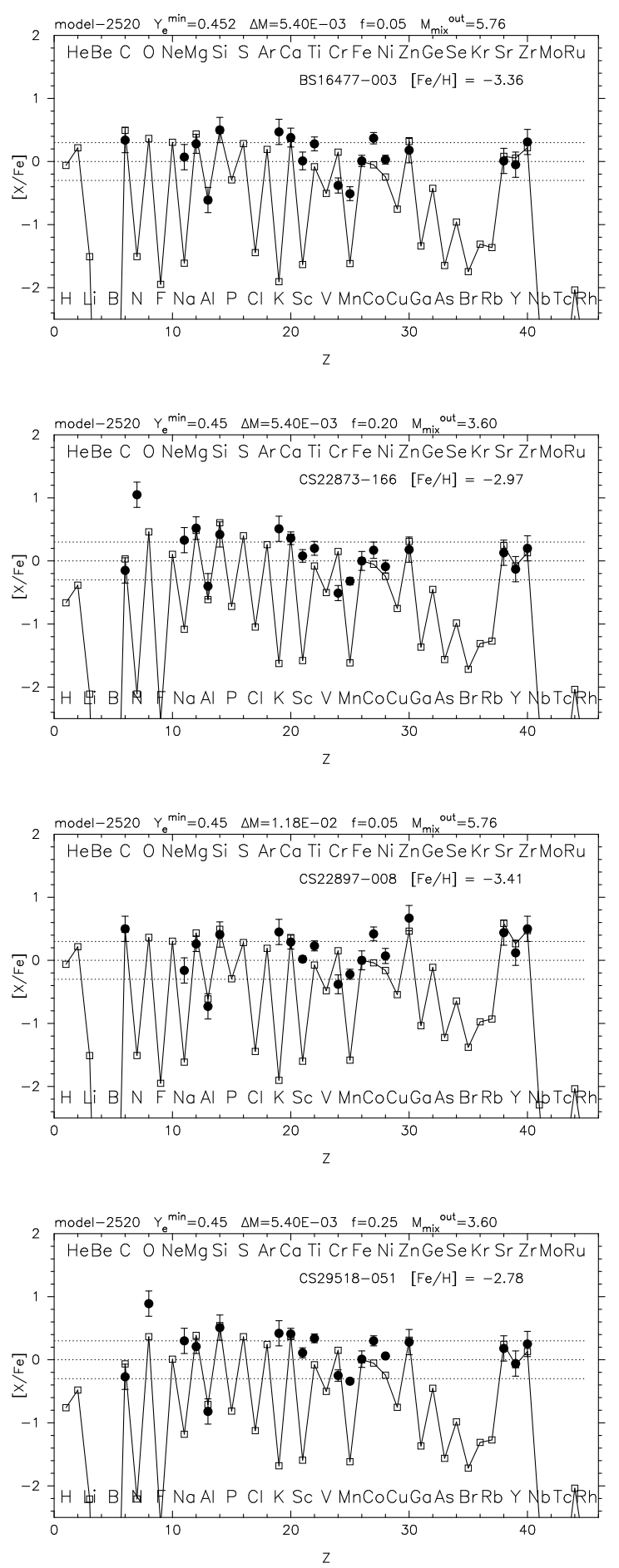

Fig. 14.- Comparisons between the yields of our mixing-fallback models and the abundance patterns of weak r-process stars. 


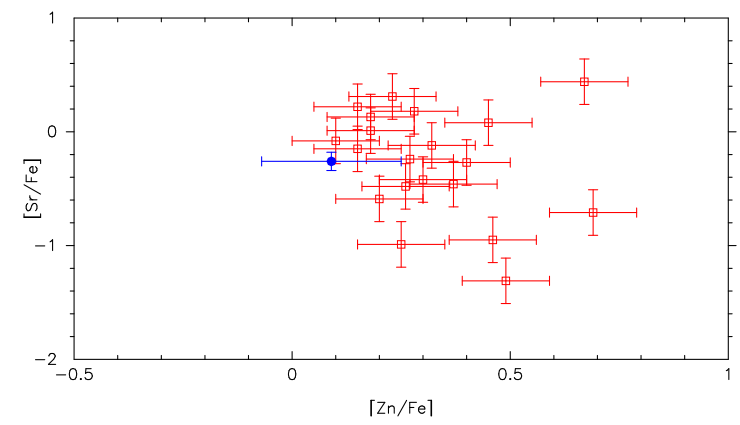

Fig. 15. - Same as Figure 1, but for $[\mathrm{Sr} / \mathrm{Fe}]$ vs. $[\mathrm{Zn} / \mathrm{Fe}]$. 